\title{
Formation of giant spicules in the deep-sea hexactinellid Monorhaphis chuni (Schulze 1904): electron-microscopic and biochemical studies
}

\author{
Werner E. G. Müller • Carsten Eckert • Klaus Kropf • \\ Xiaohong Wang • Ute Schloßmacher • \\ Christopf Seckert • Stephan E. Wolf • \\ Wolfgang Tremel $\cdot$ Heinz C. Schröder
}

Received: 25 November 2006 / Accepted: 19 February 2007 / Published online: 4 April 2007

(C) Springer-Verlag 2007

\begin{abstract}
The siliceous sponge Monorhaphis chuni (Hexactinellida) synthesizes the largest biosilica structures on earth $(3 \mathrm{~m})$. Scanning electron microscopy has shown that these spicules are regularly composed of concentrically arranged lamellae (width: 3-10 $\mu \mathrm{m}$ ). Between 400 and 600 lamellae have been counted in one giant basal spicule. An axial canal (diameter: $\sim 2 \mu \mathrm{m}$ ) is located in the center of the
\end{abstract}

Carsten Eckert was previously with the Museum für Naturkunde, Invalidenstrasse 43, 10115 Berlin, Germany.

The collagen sequence from Aphrocallistes vastus reported here, viz., [COL_APHRO] APHVACOL (accession number AM411124), has been deposited in the EMBL/GenBank data base.

This work was supported by grants from the European Commission, the Deutsche Forschungsgemeinschaft, the Bundesministerium für Bildung und Forschung Germany (project: Center of Excellence BIOTECmarin), the National Natural Science Foundation of China (grant no. 50402023), and the International Human Frontier Science Program.

W. E. G. Müller $(\varangle) \cdot$ C. Eckert · K. Kropf • U. Schloßmacher • C. Seckert $\cdot$ H. C. Schröder

Institut für Physiologische Chemie, Abteilung Angewandte

Molekularbiologie, Universität Mainz,

Duesbergweg 6,

55099 Mainz, Germany

e-mail: wmueller@uni-mainz.de

URL: http://www.biotecmarin.de/

\section{Wang}

National Research Center for Geoanalysis,

26 Baiwanzhuang Dajie,

100037 Beijing, China

S. E. Wolf $\cdot$ W. Tremel

Institut für Anorganische Chemie, Universität Mainz,

Duesbergweg 10-14,

55099 Mainz, Germany spicules; it harbors the axial filament and is surrounded by an axial cylinder $(100-150 \mu \mathrm{m})$ of electron-dense homogeneous silica. During dissolution of the spicules with hydrofluoric acid, the axial filament is first released followed by the release of a proteinaceous tubule. Two major proteins $(150 \mathrm{kDa}$ and $35 \mathrm{kDa})$ have been visualized, together with a $24-\mathrm{kDa}$ protein that cross-reacts with antibodies against silicatein. The spicules are surrounded by a collagen net, and the existence of a hexactinellidan collagen gene has been demonstrated by cloning it from Aphrocallistes vastus. During the axial growth of the spicules, silicatein or the silicatein-related protein is proposed to become associated with the surface of the spicules and to be finally internalized through the apical opening to associate with the axial filament. Based on the data gathered here, we suggest that, in the Hexactinellida, the growth of the spicules is mediated by silicatein or by a silicatein-related protein, with the orientation of biosilica deposition being controlled by lectin and collagen.

Keywords Spicules · Silica formation · Silicatein-related protein $\cdot$ Hexactinellida $\cdot$ Monorhaphis chuni (Porifera)

\section{Introduction}

The phylum Porifera (sponges) has been subdivided into three classes, viz., the Hexactinellida, Demospongiae, and Calcarea, whereby the first two taxa comprise individuals with a siliceous skeleton composed of spicules, and members of the last-mentioned taxon have calcareous (calcium carbonate) skeletal elements. Based on molecular biological (Kruse et al. 1997) and geological (Reitner and Wörheide 2002) studies, the Hexactinellida taxon has been 
established as the oldest, having evolved between Neoproterozoic glaciations (720-585 Ma), sometimes referred to as "snowball" Earth (for a review, see Corsetti et al. 2006). During this period, a cycle of silicate weathering and carbonate precipitation, prior to or simultaneously with the glaciations, has been proposed to have resulted in the dissolution of surface rocks composed of insoluble silicates $\left(\mathrm{CaSiO}_{3}\right)$. Subsequently, soluble calcium carbonate $\left(\mathrm{CaCO}_{3}\right)$ and soluble silica $\left(\mathrm{SiO}_{2}\right)$ was formed by reaction with atmospheric $\mathrm{CO}_{2}$ (Walker et al. 1981). In consequence, the level of dissolved silicic acid in seawater increased providing the inorganic starting material for the formation of siliceous spicules. Physical and chemical analyses have revealed that the siliceous skeletons of the two siliceous sponge classes are composed of amorphous silica with a water content of around 10\% (Sandford 2003). Analysis of infrared spectra have shown a distinct difference between the two taxa of between 1,080 and $1,100 \mathrm{~cm}^{-1}$ suggesting a different molecular configuration involving the Si-O-Si linkage (Sandford 2003). Other than silicic acid, only small amounts of trace elements $(<3 \%)$ are found in the spicules.

During the past few years, some aspects of the mechanism of spicule formation in Demospongiae have been clarified. Work mainly with Tethya aurantium (Shimizu et al. 1998; Cha et al. 1999) and Suberites domuncula (Krasko et al. 2000) has established that, in contrast to silica deposition in other organisms (e.g., in diatoms), biosilica formation in sponges is mediated enzymatically via the enzyme silicatein. Silicatein forms the axial filament of the spicules from which the growth of the spicules starts intracellularly (Shimizu et al. 1998; Müller et al. 2003, 2005; Wang and Wang 2006). Although marine sponges contain two isoforms of silicatein at least, freshwater sponges contain up to five silicatein isoforms, indicating the more complex formation and organization of the spicules in these animals (Müller et al. 2006). In $S$. domuncula, and probably also in other Demospongiae, spicule formation starts intracellularly. After reaching a size of approximately $6-8 \mu \mathrm{m}$, the macroscleres (spicules of $>10 \mu \mathrm{m}$ ) are extruded from the cells (sclerocytes) and completed extracellularly, where they may reach lengths of over $100 \mu \mathrm{m}$ (Müller et al. 2005). In the extracellular space, both the final longitudinal size and the final thickness of the spicules are reached by appositional growth (Müller et al. 2006). These processes are mediated by silicatein and controlled by galectin, which acts as an organic matrix for the attachment of silicatein molecules (Schröder et al. 2006). Collagen probably provides the structural groove along which the galectin-silicatein strings are guided, thus allowing the formation of the intricately architectured spicules (Eckert et al. 2006).

The monophyletic group of Hexactinellida is, according to the form and organization of its spicules, divided into two subclasses: the Hexasterophora and Amphidiscophora (for a review, see Reiswig 2006). In the latter subclass, amphidiscs are the (main) microscleres and never fuse. One member of this subclass is the family Monorhaphididae, which includes three described species: Monorhaphis chuni, $M$. dives, and $M$. intermedia. Since the discovery of these sponges during the first German deep-sea expedition (RV "Valdivia") and the first descriptions of these animals by Chun (1900) and Schulze (1904), only little additional information has been added regarding the form and construction of their skeletal systems. Nothing has been published concerning the synthesis of their giant spicules. Worldwide, M. chuni has been documented only at a few sampling sites (Tabachnick 2002), suggesting a distribution in the deep sea in the Indian Ocean and in the West Pacific. One outstanding feature of Monorhaphis is its anchoring spicule, which can reach lengths of up to $3 \mathrm{~m}$ with a maximum diameter of $8.5 \mathrm{~mm}$ (Schulze 1904). M. chuni thus produces the largest biosilica structure known on Earth. Polished cross sections confirm the existence of up to 500 highly regular concentric rings that are arranged around a $150-\mu \mathrm{m}$-thick less-structured core (Schulze 1904). In the middle of this core, a square axial channel with a proteinaceous filament of approximately $2 \mu \mathrm{m}$ in thickness is visible running through the entire spicule from one end to the other. The concentric rings around this core have nearly constant thickness in all samples, but this thickness varies among sampling locations; for example, from the Somalia basin, silica strata are $8-10 \mu \mathrm{m}$ in thickness, whereas those from the Madagascar basin are 3-5 $\mu \mathrm{m}$ thick.

Recently, Aizenberg et al. (2005) have published a detailed structural analysis of the spicule formation in the hexactinellid Euplectella. They have demonstrated structural hierarchies of spicule synthesis starting from the nanometersized particles of silica to the final mature spicules. The composition of the proteins that are associated with and found within the spicules has not been described. In a recent study, Ehrlich et al. (2005) dissolved the basal spicules of the hexactinellid Hyalonema sieboldi in $2.5 \mathrm{M} \mathrm{NaOH}$ at $30^{\circ} \mathrm{C}$ for 14 days and were able to show that the abundant structural protein associated with the spicules was probably collagen with an $\mathrm{M}_{\mathrm{r}}$ of around $130 \mathrm{kDa}$. However, whether degradation of the collagen fibrils occurred during the dissolution of silica with $\mathrm{NaOH}$ remained unclear. In continuation of these studies, we have analyzed the protein composition of the spiculeassociated protein(s) in the spicules of $M$. chuni and $M$. intermedia; the results are presented here.

We present a microscopic analysis of the spicules from $M$. chuni with major emphasis on the giant spicules (giant basal spicules or basalia: $1 \mathrm{~m}$ ) and also the large comitalia $(\sim 60 \mathrm{~mm})$. This is followed by an examination of the organic components of these spicules, including the collagen fibrils that surround these spicules. Data obtained from electron 
microprobe analysis are given that show the regionally different composition of sodium and potassium within the spicules. After dissolution of the spicules, several proteins have been visualized: one cross-reacts with antibodies raised against silicatein, whereas others display proteolytic activity. After having substantiated, by molecular biological techniques, that Hexactinellida possess at least one gene coding for collagen (cDNA from the hexactinellid Aphrocallistes vastus), we provide a schematic outline of spicule growth, both in the longitudinal and the axial direction.

\section{Materials and methods}

\section{Materials}

Enzymatic CarboRelease kit (No. KEDG-01) was obtained from QA-Bio (Novatec, Basel, Switzerland); electrophoresis loading buffer (RothiLoad4) from Roth (Karlsruhe, Germany); Sypro Ruby protein gel stain from BioRad (München, Germany); casein and Coomassie Brilliant Blue from Serva (Heidelberg, Germany); Sirius Red [3BA], tetraethoxysilane (TEOS), and Rhodamine 123 from SigmaAldrich (Taufkirchen, Germany); horse blood from Fiebig Nährstofftechnik (Germany); and GelCode blue from Perbio (Bonn, Germany).

\section{Sponges}

Specimens of the hexactinellid M. chuni (Schulze 1904; Porifera:Hexactinellida:Amphidiscosida:Monorhaphididae) were collected by dredging at a depth of 1,600 m, during the Valdivia Expedition off the coast of East Africa (Somalia basin). The syntype identified and described by Schulze (1904) is shown in Fig. 1a-c. The examined type specimen originates from the collection of the Zoological Institute in Leipzig and is kept at the Museum für Naturkunde Berlin, Germany (ZMB Por 12700). The spicule fragment has a length of $30 \mathrm{~cm}$ (Fig. 1a,b) with a maximum diameter of $6 \mathrm{~mm}$ (Fig. 1c). Further samples from a depth of $700 \mathrm{~m}$ obtained by a Soviet deep-sea cruise (RV "Vitjaz II", cruise no. 17) off the east coast of Madagascar and from a depth of $600 \mathrm{~m}$ by a French cruise (RV “Coriolis", Musorstom 5) off New Caledonia (Fig. 1d) were also examined (kindly provided by Dr. K. Tabachnick, Institute of Oceanology Moscow, Russia). In addition, specimens of $M$. intermedia ( $\mathrm{Li}$ 1987), dredged from $800 \mathrm{~m}$ in the Okinawa Trough were given by Prof. J. Li (Institute of Oceanology, Academia Sinica, Qingdao, China). The Demospongiae Suberites domuncula (Porifera: Demospongiae:Hadromerida) and Geodia cydonium (Porifera:Demospongiae:Tetractinomorpha:Astrophorida) were collected in the Adriatic Sea.

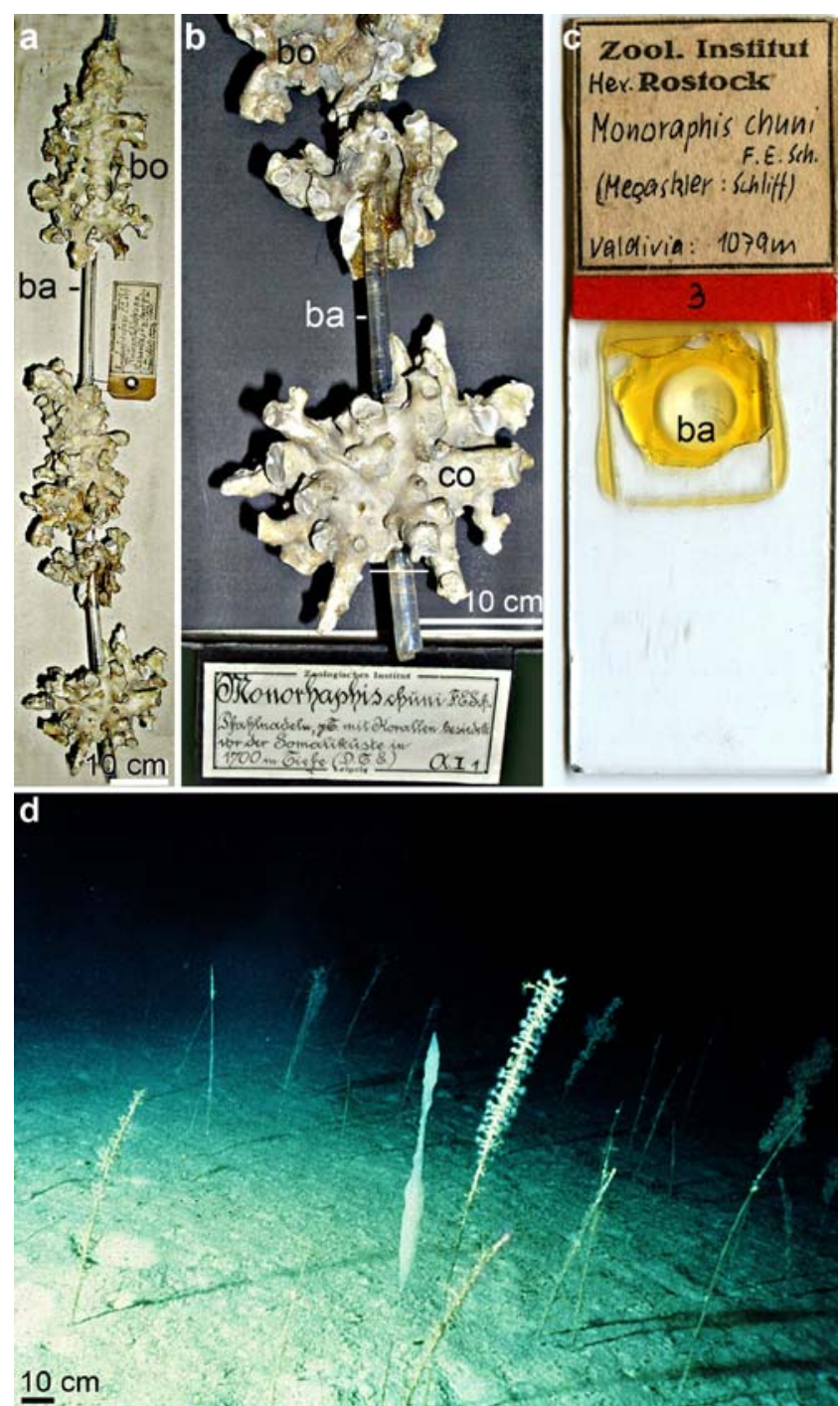

Fig. 1 Monorhaphis chuni. a Syntype used for the description by Schulze (1904); the specimen was collected in 1899 at a depth of $1,700 \mathrm{~m}$ from the deep-sea bottom during the Valdivia expedition in the Somali basin. Size: $45 \mathrm{~cm}$. The animal consists of a giant basal spicule ( $b a$ basalia) around which the body of the animal $(b o)$ is arranged. The giant basal spicules are megascleres and anchor $M$. chuni to the substratum. This specimen is the syntypus determined by Schulze (1904; Museum für Naturkunde, Berlin; ZMB Por 12700). b Higher magnification of the basal part of the giant basal spicule, which attaches the sponge into the ground; the spicule is associated with stony corals $(c o)$. c Cross section through the giant basal spicule ( $8 \mathrm{~mm}$ thick), prepared by F.E. Schulze (University of Rostock, Institute of Zoology). d M. chuni in its natural soft bottom habitat of bathyal slopes off New Caledonia (photograph taken by Michel Roux, University of Reims; reproduced with permission). The specimens live at a depth of 800-1,000 m (Roux et al. 1991). In this region, the sponge occurs at a population density of $1-2$ individuals per $\mathrm{m}^{2}$. The animals reach sizes of around $1 \mathrm{~m}$ in length

For the isolation of the cDNA encoding collagen, a cDNA library of Aphrocallistes vastus (Hexactinellida: Hexasterophora:Hexactinosida:Aphrocallistidae) was used (Gundacker et al. 2001). 
Extracts from spicules of $M$. chuni, S. domuncula, and G. cydonium for the determination of proteolytic activity in the spicules were prepared as described by Schröder et al. (2006) and involved grinding the spicules in TRIS-buffered saline $\mathrm{pH} 7.5$ (TBS) with $1 \mathrm{mM}$ EDTA, 1\% Nonidet-P40, supplemented with $4 \mathrm{M}$ urea. After centrifugation, the supernatant was used for zymogram analysis.

\section{Electron microscopy}

Scanning electron microscopy (SEM) analysis of spicules was performed with a Zeiss DSM 962 Digital Scanning Microscope (Zeiss, Aalen, Germany). The samples were mounted onto aluminum stubs (SEM-Stubs G031Z; Plano, Wetzlar, Germany) that had been covered with adhesive carbon (carbon adhesive Leit-Tabs G3347). These preparations were then sputtered with a 20-nm layer of gold in an Argon plasma (Bal Tec Med 020 coating system; Bal Tec, Balzers, Liechtenstein). The surfaces of spicule cross sections had been polished with emery paper (silicon carbide; Matador, Hoppenstedt, Darmstadt, Germany), the quality of the surface having been inspected under a stereomicroscope (enlargement: about $30 \times$ ). Backscattered analysis was performed with this microscope and by using $15-\mathrm{KeV}$ beam voltage and $50-\mu \mathrm{A}$ emission current at a working distance of $6 \mathrm{~mm}$ (Holmes et al. 1987).

\section{Electron microprobe procedure}

Thin sections $(150 \mu \mathrm{m})$ of giant basal spicules were prepared and subjected to electron microprobe analyses as described by Sommer et al. (2003). Mineral analyses were performed by means of a JOEL 8900RL Superprobe device attached to a MICROSPEC wavelength dispersive system. Matrix correlations for silicates were achieved by using the ZAP procedure and natural mineral standards.

Spicule dissolution

Stepwise dissolution The sequential release of the organic material from the giant basal spicules collected in 1898 (Schulze 1904) was analyzed as described previously (Müller et al. 2006). The spicules still contained residual layers of surface collagen-like sheaths. Spicules were placed onto glass slides and etched by being covered with $4 \mathrm{M}$ hydrofluoric acid (HF). To visualize the released proteins, Coomassie solution $[0.1 \%(\mathrm{w} / \mathrm{v})$ Coomassie Brilliant Blue $250,40 \%$ methanol, $10 \%$ acetic acid] was added. Photographs were taken at various times of incubation (up to 40 min) via an Olympus AHBT3 microscope.

Complete dissolution Tissue from M. chuni was dissolved in sulfuric/nitric acid (3:1), and the spicules were washed with distilled water. For the complete dissolution of silica from the cleaned spicules, they were treated with $2 \mathrm{M} \mathrm{HF}$, $8 \mathrm{M} \mathrm{NH}_{4} \mathrm{~F}$, pH 5 (Shimizu et al. 1998) at room temperature overnight. The axial filaments and the associated proteins were collected by centrifugation $\left(20,000 \mathrm{~g}, 10 \mathrm{~min}, 4^{\circ} \mathrm{C}\right)$. The sediment was dialyzed against distilled water as described by Shimizu et al. (1998).

Where indicated the spicules were stained with Sirius Red for collagen as described by Junqueira et al. (1979).

SDS-polyacrylamide gel electrophoresis and Western blot analysis

Protein samples $(25 \mu \mathrm{g})$ were taken from the axial filament after complete dissolution of the spicules with HF, dissolved in loading buffer (Roti-Load; Roth, Karlsruhe, Germany), boiled for $5 \mathrm{~min}$, and then subjected to $10 \%$ polyacrylamide gel electrophoresis (PAGE) with $0.1 \%$ sodium dodecyl sulfate (SDS-PAGE). After separation, the gels were washed in $10 \%$ methanol (supplemented with $7 \%$ acetic acid) for $30 \mathrm{~min}$, stained in Sypro Ruby protein gel stain overnight, and finally inspected under ultraviolet light (excitation wavelength: $302 \mathrm{~nm}$ ).

For Western blot analysis, the polypeptides were transferred to polyvinylidene fluoride (PVDF) membranes (Millipore-Roth, Karlsruhe; Germany) and reacted with polyclonal antibodies (PoAb) raised against silicatein from $S$. domuncula as described earlier (termed PoAb-aSILIC; Müller et al. 2005). The PVDF membranes were then rinsed in TBS-T (20 mM TRIS- $\mathrm{HCl} \mathrm{pH} 7.6,137 \mathrm{mM} \mathrm{NaCl}$, $0.1 \%$ Tween-20) and incubated for $1 \mathrm{~h}$ with PoAb-aSilic (1:1,000 dilution) diluted in TBS-T supplemented with 5\% non-fat dry milk and $1.5 \%$ bovine serum albumin. Membranes were washed three times in TBS-T and then incubated for $1 \mathrm{~h}$ with anti-rabbit IgG (alkaline phosphatase conjugate; 1:2,000 dilution; Sigma). Immunocomplexes were visualized with the NBT/BCIP color development system (Roth; nitroblue tetrazolium/5-bromo-4-chloro-3-indolyl phosphate). For controls, we used pre-adsorbed PoAb-aSILIC $(100 \mu \mathrm{l}$ antibodies were incubated with $20 \mu \mathrm{g}$ recombinant silicatein rSILIC SUBDO). This antibody preparation gave no signals in Western blots (Schröder et al. 2006). A protein sizestandard (Dual Color; Roth) was used to estimate the size of the proteins.

Deglycosylation of proteins of giant basal spicules

Total extracts from spicules after dissolution of silica by HF were subjected to enzymatic deglycosylation by applying the CarboRelease reaction kit. The proteins of the spicules dissolved in $50 \mathrm{mM}$ Na-phosphate $(\mathrm{pH} 7.0)$ were denatured 
by incubating the samples at $95^{\circ} \mathrm{C}$ for $5 \mathrm{~min}$. Subsequently, the samples were incubated at $37^{\circ} \mathrm{C}$ for $3 \mathrm{~h}$ with the enzyme cocktail of the CarboRelease reaction kit (PNGase), which consisted of N-glycosidase F (Chryseobacterium meningospeticum; specific activity: $5 \mathrm{mU}$ ), O-glycosidase (Streptococcus pneumoniae; $1.25 \mathrm{mU}$ ), sialidase (Arthrobacter ureafaciens; $5 \mathrm{mU}), \beta$-galactosidase (S. pneumoniae; $50 \mathrm{mU}$ ), and glucosaminidase (S. pneumoniae; $1 \mathrm{mU})$. The reaction products were then analyzed by electrophoresis by SDS-PAGE as described above.

Analysis of proteolytic activity in spicular extracts

Proteins were released from giant basal spicule after complete HF dissolution and examined for protease activity by zymogram analysis. Prior to this procedure, the extract was dialyzed against phosphate-buffered saline and subsequently loaded onto the zymogram gel, which contained $0.1 \%$ casein, essentially as described by Jaffe and Dwyer (2003). The samples were separated by SDS-PAGE (12\% gels). Samples of $15 \mu$ l were loaded onto each gel, corresponding approximately to a protein extract from $400 \mu \mathrm{g}$ spicules. After separation, the gels were incubated in renaturation buffer (50 mM MOPS pH 6.8, $5 \mathrm{mM} \mathrm{CaCl}_{2}$, $0,1 \mathrm{mM} \mathrm{ZnCl} 2,100 \mathrm{mM} \mathrm{NaCl}, 0,5 \mathrm{mM}$ dithiothreitole) for $1 \mathrm{~h}$ at room temperature. After this buffer had been refreshed, protease activity was allowed to develop overnight at $37^{\circ} \mathrm{C}$. The gels were then stained with Coomassie Brilliant Blue in order to visualize protease activity as clear bands on a blue background.

The following samples were tested: extracts from spicules of $M$. chuni and from the Demospongiae $G$. cydonium and $S$. domuncula. In one series of experiments, the M. chuni extract was heated at $95^{\circ} \mathrm{C}$ for 5 min prior to application onto gels.

\section{Cloning of cDNA for collagen from A. vastus}

The complete collagen [COL_APHRO], APHVACOL, was isolated from a cDNA library of $A$. vastus, which was prepared in lamda ZAP Express and packaged in vitro with the MaxPlaxTM Packaging Extract as described by Gundacker et al. (2001). A degenerate forward primer was designed against the collagen-specific amino acid (aa) triplets. The polymerase chain reaction (PCR) was carried out with this primer and a vector primer at an initial denaturation at $95^{\circ} \mathrm{C}$ for $5 \mathrm{~min}$, followed by 35 amplification cycles at $95^{\circ} \mathrm{C}$ for $30 \mathrm{~s}, 52^{\circ} \mathrm{C}$ for $45 \mathrm{~s}$, and $71^{\circ} \mathrm{C}$ for $1.5 \mathrm{~min}$, with a final extension step at $74^{\circ} \mathrm{C}$ for $10 \mathrm{~min}$. Fragments were obtained and cloned into the TOPO TAII vector in Escherichia coli TOP10 cells. Sequencing was performed with primers directed to the SP6 promoter (5'ATTTAGGTGACACTATAG- $3^{\prime}$ ) and the T7 promoter (5'-
TAATACGACTCACTATAGGG-3'). The sequence was completed with insert-specific primers in combination with 5'-RACE (rapid amplification of cDNA ends) primer (5'GTCTACCAGGCATTCGCTTCAT-3') or with $3^{\prime}$-RACE primer (5'-CTGTGAATGCTGGACTACGAT-3') by using the CapFishing Full-length cDBA Premix Kit. The final sequence was confirmed by an additional PCR with primers directed against the non-translated region of the cDNA, followed by sequencing. The clone encoding $A$. vastus collagen was 2,610 nucleotides (nts) long, excluding the poly(A) tail.

\section{Sequence analyses}

The sequences were analyzed with computer programs BLAST (2005; http://www.ncbi.nlm.nih.gov/blast/blast.cgi) and FASTA (2005; http://www.ebi.ac.uk/fasta33/). Multiple alignments were performed with CLUSTAL W Ver. 1.6 (Thompson et al. 1994). Phylogenetic trees were constructed on the base of aa-sequence alignments by neighbor-joining, as implemented in the Neighbor program from the PHYLIP package (Felsenstein 1993). The distance matrices were calculated by using the Dayhoff PAM matrix model as described (Dayhoff et al. 1978). The degree of support for internal branches was further assessed by bootstrapping (Felsenstein 1993). The graphic presentations were prepared with GeneDoc (Nicholas and Nicholas 1997).

\section{Analytical method}

The Bradford method (Compton and Jones 1985; RotiQuant solution, Roth) was used for the quantification of protein.

\section{Results}

Spicule organization of $M$. chuni

The body of M. chuni (choanosomal body), which is arranged around a giant single basal spicule (up to $3 \mathrm{~m}$ long), contains 14 further siliceous spicule types with lengths ranging from a few micrometers to $50 \mathrm{~mm}$; the latter spicules stabilize the tissue that filtrates particulate food through the aqueous canal system of the animal. The body of the sponge has an oblong, laterally compressed shape. The giant basal spicule is also termed a basalium (Fig. 1a,b). The choanosomal body comprises mainly triactines (tauactines), diactines, and amphidiscs (for examples, see Fig. 2). Figure 2a shows a hexactin spicule of the choanosome with six nonbranched rays arranged perpendicular to one another; this represents the archetype 

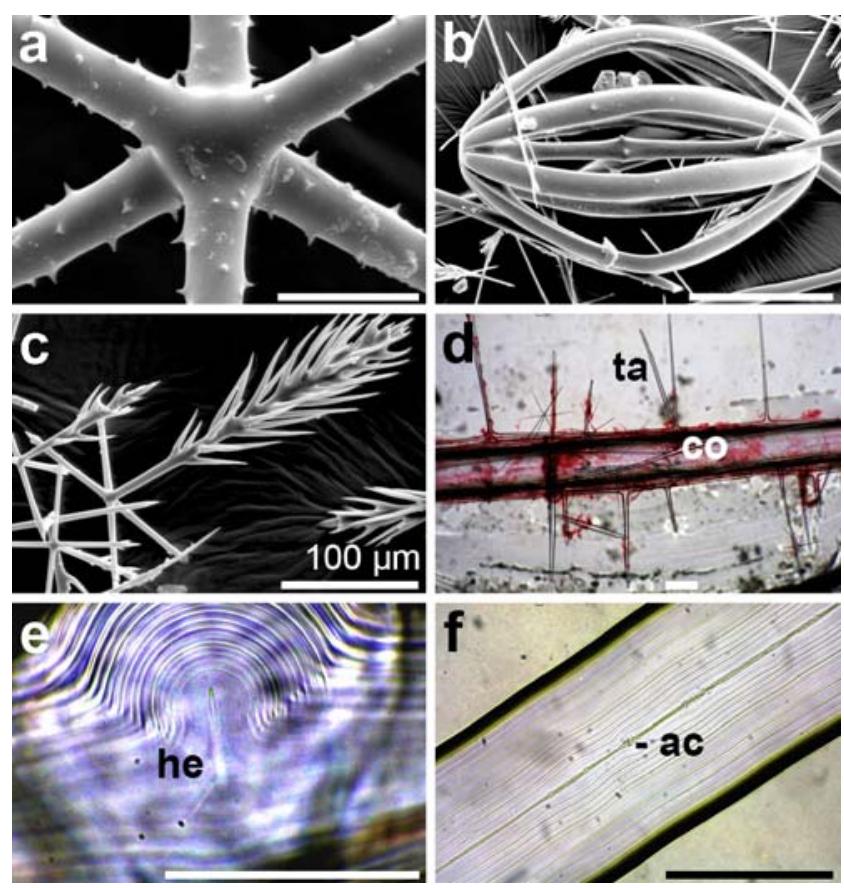

Fig. 2 Spicules of the choanosomal body from M. chuni. a Hexactin spicule comprising the six characteristic, perpendicularly arranged, unbranched rays. b Macramphidisc with its dumb-bell-shaped diactin microscleres. c Pinular pentactin spicules, which stabilize the canal system. d Many tauactin ( $t a$ ) spicules are arranged onto one comitalia $(c o)$. Around the tauactin, collagen fibers are stained red (Sirius Red for collagen). e At distances of approximately $200 \mu \mathrm{m}$, the comitalia show a central swelling within the lamellar arrangement of the silica layers. In these swellings, cryptic silica structures exist that display a hexactin structure (he). f In a longitudinal view of the comitalia, the lamellar arrangement of the silica layers is seen around the 2- to 4- $\mu \mathrm{m}$-thick axial canal (ac). Bars $100 \mu \mathrm{m}$

of hexactinellid scleres. In Fig. 2b, a macramphidisc is shown that is composed of dumb-bell-shaped diactin microscleres. These scleres are restricted to the order Amphidiscosida (Schrammen 1924). Finally, dermal pinular pentactin spicules (Fig. 2c) are shown; these line the canal system of $M$. chuni and contribute to the efficient filtration system of the animals.

The largest spicules in the body of M. chuni are the comitalia, the parenchymal diactin spicules. The comitalia are located in the choanosome and reach lengths up to $60 \mathrm{~mm}$ and diameters of $100 \mu \mathrm{m}$ (Fig. 2d). The surface of the comitalia is covered by a net of collagen, which is stained red with the Sirius Red stain. Tauactin spicules are arranged around the comitalia (Fig. 2d). At distances of approximately $200 \mu \mathrm{m}$, the comitalia show central swellings within the lamellar arrangement of the silica layers. In these swellings, cryptic silica structures can be visualized that comprise hexactin structures (Fig. 2e). Like the other spicules, the comitalia are also composed of lamellar layers of silica arranged around the 2- to 4- $\mu \mathrm{m}$ thick axial canal (Fig. 2f).
Lamellar layer organization of comitalia and basalia

The organization and arrangement of the silica layers of the comitalia are similar to the concentric layering of the giant basal spicules (basalia). Whereas the basalia reach sizes of up to $3 \mathrm{~m}$, the comitalia are relatively short at $60 \mathrm{~mm}$ (see also above).

A diagonal SEM analysis of a broken comitalia shows the fracture surface. Operationally, we distinguish between 20 - to $40-\mu \mathrm{m}$-thick primary silica layers (Fig. 3a-c); these layers are built up by 10-20 smaller secondary silica layers of a thickness of around $3 \mu \mathrm{m}$. Cross sections through giant basal spicules show the structural division of the spicules. First, the axial canal is located at the center of the spicules and harbors the axial filament. Second, around this canal, an axial cylinder of $100-150 \mu \mathrm{m}$ can be distinguished; this is built from electron-dense homogeneous silica. The cylinder is surrounded by 300-500 lamellae (3-5 $\mu \mathrm{m}$ thick), which are regularly and concentrically arranged (Fig. 3d,e). The giant basal spicules are occasionally decorated by rectangular protrusions that are composed of lamellae and that parallel these structures, especially below the surface (Fig. 3f).

The inter-lamellar zone of the spicules is surprisingly not formed by a continuous open slit (Fig. 3g). The interlamellar zone (width: $0.1-0.2 \mu \mathrm{m}$ ) is composed of open holes and fusion zones that allow a continuum between two silica lamellae (Fig. 3h,i). This structural organization is seen more frequently between the lamellae of the spicules.

Arrangement of collagen layers around spicules

The surfaces of all spicules found in M. chuni are surrounded by a net of collagen. Because of the size of the spicules, morphological studies with the tauactins (120-350 $\mu \mathrm{m}$ long and $40 \mu \mathrm{m}$ thick) are more favorable (Fig. 4). The net usually covers the complete surface of the spicule but leaves the tips of the tauactins open; the uncovered area at the tip is approximately $40 \mu \mathrm{m}$ long (Fig. 4a). The collagen net is regularly interrupted by circular holes $(7-10 \mu \mathrm{m})$, which cannot be considered artifacts, since they have been found on spicules from several specimens. Using higher magnifications, we have observed that the fibrils are uniform in size and shape. The diameter of the fibrils is approximately $25 \mathrm{~nm}$ and, with a periodicity of $65 \mathrm{~nm}$, the fibrils can enlarge, forming large nodules of $40 \mathrm{~nm}$ (Fig. 4e,f).

Other than in Demospongiae, the tips of the spicules are not completely covered by silica layers but show a square opening with a diameter of 2-3 $\mu \mathrm{m}$ (Fig. 5a-2, a-3). In most cases, the orifice, which represents the axial canal of the spicules, is not filled with any visible material. Tips of open spicules only rarely show the axial filament (Fig. 5a-1). 

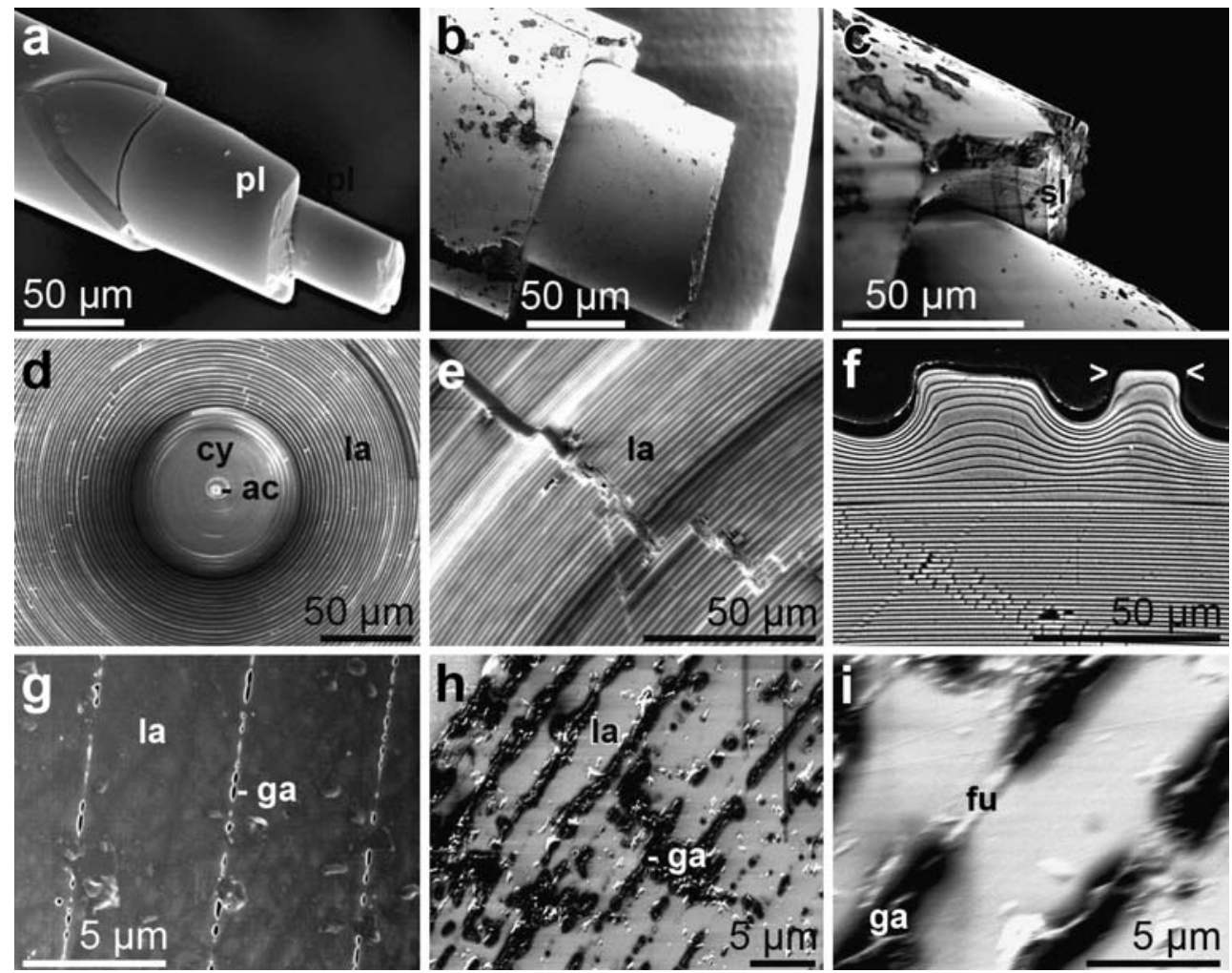

Fig. 3 Concentric organization of the silica layers of comitalia $(\mathbf{a}-\mathbf{c})$ and giant basal spicules (d-i) from $M$. chuni. a-c Diagonal SEM analyses show the fracture surface of comitalia with primary silica layers $(p l)$ of $20-40 \mu \mathrm{m}$ thickness. At higher magnification (c), the fracture surface of comitalia with their primary layers $(20-40 \mu \mathrm{m}$ thick) are seen to be composed of 10-20 thinner secondary silica layers $(s l)$ with a thickness of $\sim 3 \mu \mathrm{m}$. d-i Giant basal spicules (basalia). d Polished cross section with three parts: the axial canal $(a c)$ in which the axial filament is located, the axial cylinder $(c y)$ formed by

dense homogeneous silica, and the main part of the spicule with regularly arranged concentric silica lamellae $(l a)$. e Higher magnification of the lamellar region $(l a)$. $\mathbf{f}$ In some regions, the surface of the giant basal spicules shows rectangular protrusions (between arrowheads) formed by forwarded lamellae. $g$ Higher magnification to show the inter-lamellar zone of the spicules. Between the lamellae (la), a gap ( $g a$ ) exists formed by open holes. h These holes fuse after variable distances. i SEM image of the inter-lamellar zone showing the electron fusion zones $(f u)$ composed of silica separating the holes

\section{Electron microprobe analysis}

Thin sections $(150 \mu \mathrm{m})$ of giant basal spicules were analyzed by electron microprobe analyses. Spicules with a diameter of $1.7 \mathrm{~mm}$ were subjected first to SEM analysis (Fig. 6, top image) and subsequently analyzed with an electron microprobe analyzer (Fig. 6, three bottom images). In the central

area of the spicules, the dominant element was silicon $(\mathrm{Si})$ with 85-89 wt \%; lower concentrations were measured for sodium $(\mathrm{Na})$ with $0.02-0.05 \mathrm{wt} \%$ and for potassium $(\mathrm{K})$ with $0.8-1.3 \mathrm{wt} \%$. In the outer region (up to approximately $200 \mu \mathrm{m}$ from the surface), the Si content was $84-86 \mathrm{wt} \%$; the concentration of $\mathrm{Na}$ was $0.42-0.52 \mathrm{wt} \%$, and that of $\mathrm{K}$ was $0.28-0.41 \mathrm{wt} \%$. In all areas of the spicules, the

Fig. 4 Collagen coat covering the surface of the spicules, using the tauactins as examples; SEM analysis. a-d Collagen ( $\mathrm{col}$ ) nets, surrounding the spicules, show a tight mat of fibrils. This sheet is regularly interspersed with large holes of 7-10 $\mu \mathrm{m}(h)$. e, f At higher magnification, the collagen bundles with a diameter of $25 \mathrm{~nm}$ become visible. The fibrils expand up to $40-\mathrm{nm}$ nodules with a periodicity of $65 \mathrm{~nm}$
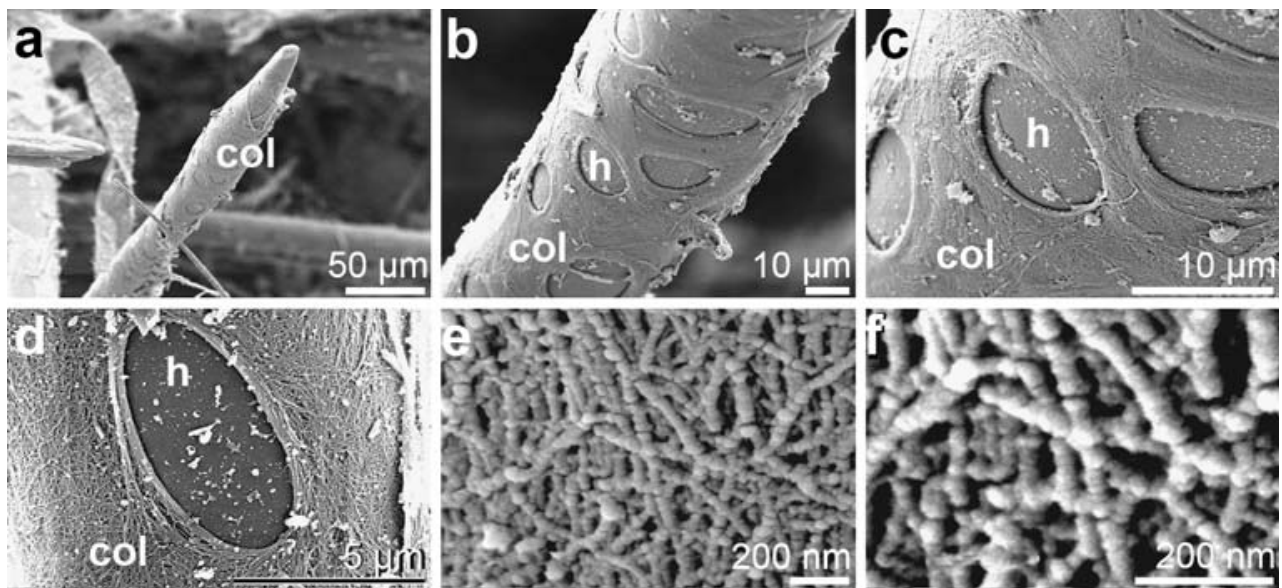

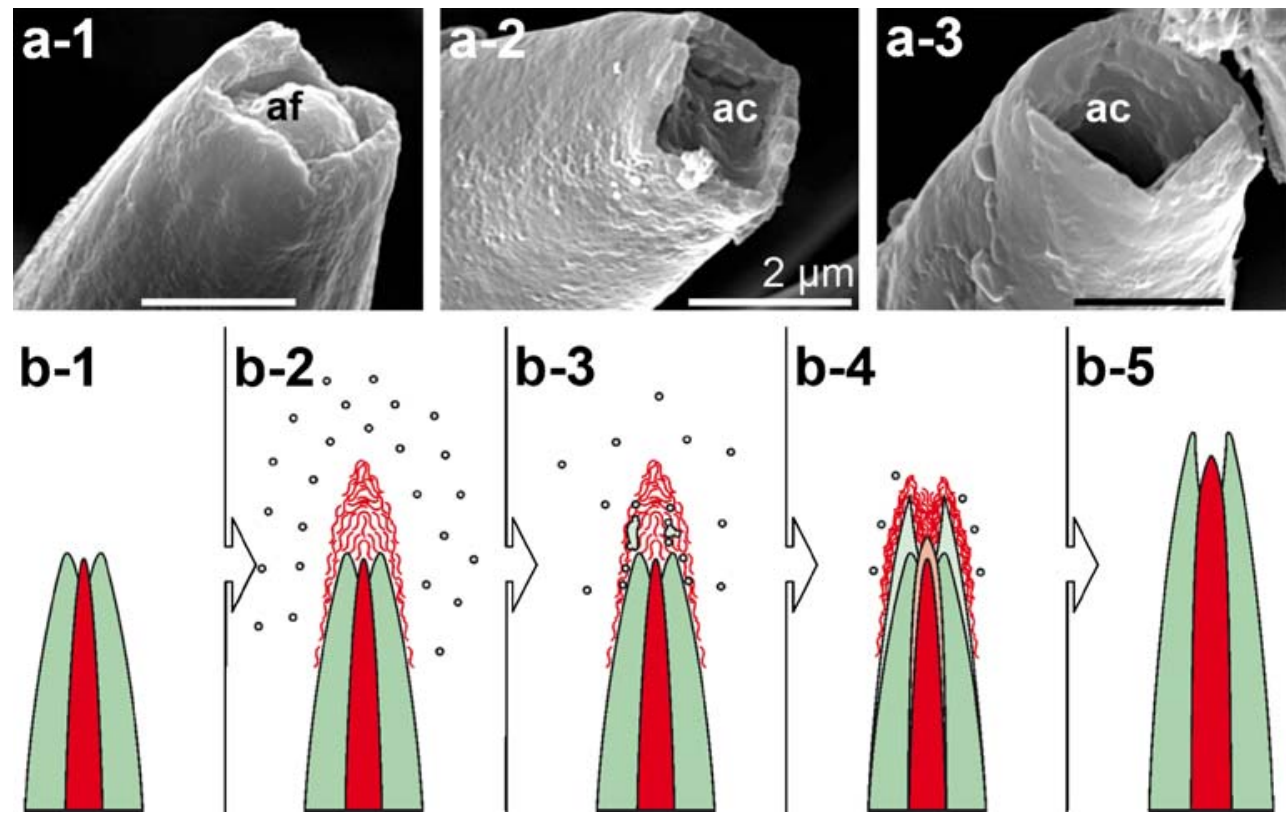

b-5

Fig. 5 Tauactin spicules with open tips. a-1-a-3 All spicules in hexactinellides contain a quadratic opening, the axial canal (ac); SEM analysis. The quadrangular axial filament $(a f)$ is connected with the outer surface of the spicules and allows them to grown in length; it also determines the direction of spicule formation. Whereas in most spicules, the opening does not contain any material (a-2, a-3), the axial canal of some spicules contains an axial filament ( $a f ; \mathbf{a}-\mathbf{1})$. b-1, b-2 Representation of the longitudinal growth of the spicules. $\mathbf{b}-\mathbf{1}$ In the

concentration of other elements, e.g., $\mathrm{Fe}, \mathrm{Ba}, \mathrm{Al}, \mathrm{Mg}, \mathrm{Ca}$, and $\mathrm{Sr}$ was lower than $0.02 \mathrm{wt} \%$. The rest of the element distribution (to $100 \%$ ) was attributed to carbon, which could not be determined reliably with this technique.

initial stage, the spicule with its silica layers (dark green) has, within its axial canal, the axial filament (red), which reaches almost to the tip of the spicule. b-2, b-4 During the growth of the spicule, silicatein-like material mediates the deposition of the polymeric silica (green dots and patches), which is deposited as a new layer on top of the previous silica layer (light green). b-4, b-5 With progress of the axial growth of the spicules, the organic material becomes internalized into the spicule and contributes to the elongation of the axial filament

Wavelength-dispersion mapping with an electron microprobe also indicated the high concentration of Si throughout the spicule (Fig. 6). For K, the level was higher at the central part and dropped drastically at the rim of the spicule

Fig. 6 Electron microprobe analysis of a giant basal spicule. Top SEM analysis of the spicule (left central part, right surface region). Middle, bottom Wavelength-dispersive maps of the same areas of the carboncoated surface for silicon $(\mathrm{Si})$, potassium $(\mathrm{K})$, and sodium $(\mathrm{Na})$. The concentrations of the elements increase from blue through green to yellow and finally to red. Absolute values for the respective elements, measured at the indicated areas, are given left and right (in $\mathrm{wt} \%$ ). Bar $200 \mu \mathrm{m}$

\section{axial canal}

surface

SEM

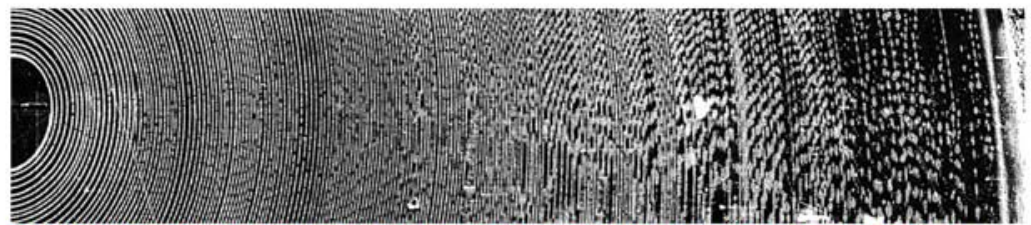

Si

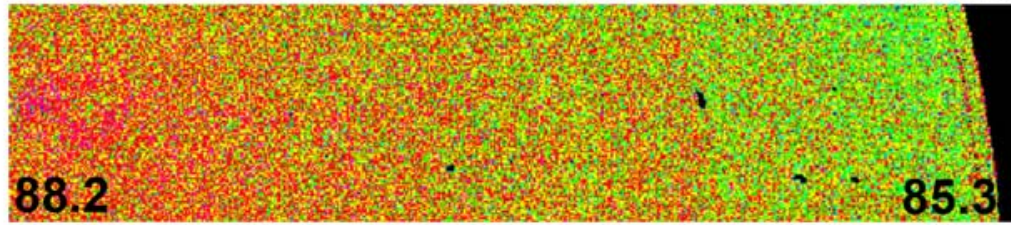

$w t \%$

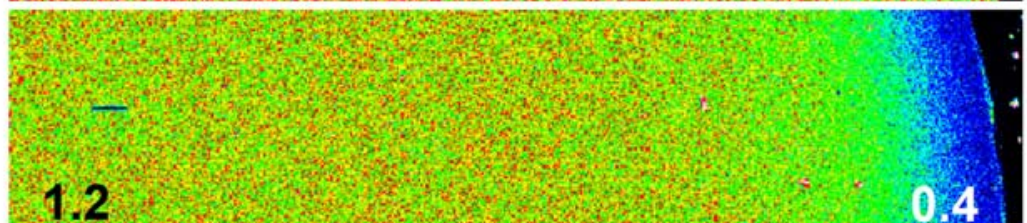

$\mathrm{Na}$

wt $\%$

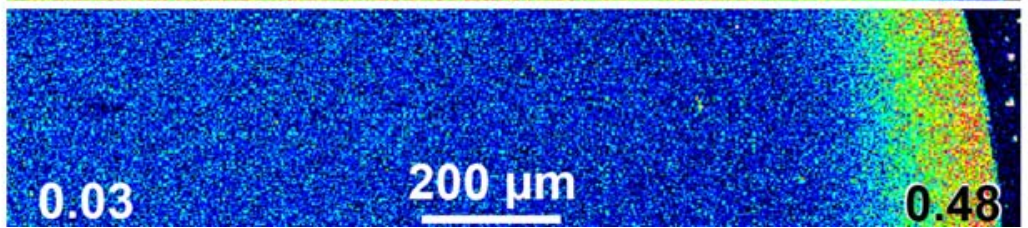


(Fig. 6). An inverted distribution was measured for Na: low at the center and high at the surface of the spicules (Fig. 6).

Analysis of proteins contained in spicules

The proteins in the spicules were sequentially released by dissolving the silica material in HF. To visualize the proteins released during this process, Coomassie Brilliant Blue was added (Fig. 7). Residual collagen was immediately stained (Fig. 7a), whereas the axial filament appeared subsequently (Fig. $7 \mathrm{a}-\mathrm{c}$ ). The first appearance of the axial filament was seen after 3 min (Fig. 7a) and its exposure increased steadily. After a period of more than $25 \mathrm{~min}$, a 5-mm-long filament was uncovered from the siliceous shell (Fig. 7d). Of note, after completion of the dissolution process, a proteinaceous tube was exposed (Fig. 7d) that disintegrated, following an additional period of $45 \mathrm{~min}$, to a fibrous network (not shown).

Proteins were obtained from the giant basal spicule after dissolution with HF and analyzed by SDS-PAGE. After staining the gels, two major protein bands with sizes of $150 \mathrm{kDa}$ and $35 \mathrm{kDa}$ became visible. Several minor bands within the size range of 50-250 $\mathrm{kDa}$ were likewise present (Fig. 8a; lane a). A faint band was seen with a size of $24 \mathrm{kDa}$.

\section{Deglycosylation of spicular proteins and Western blot} analysis

The proteins released from the giant basal spicules were deglycosylated enzymatically and likewise separated by SDS-PAGE. The most obvious shift in the size of the
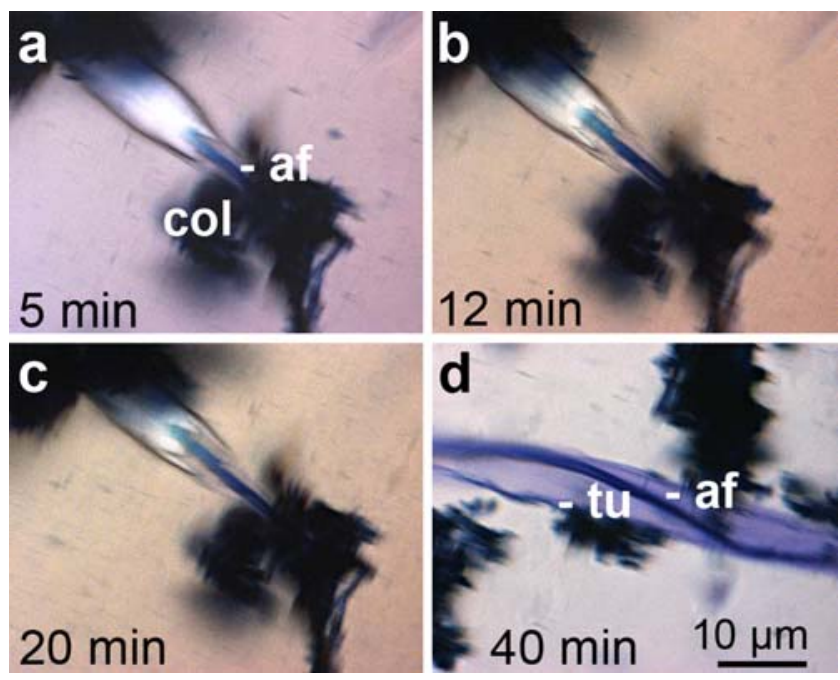

Fig. 7 Dissolution of giant basal spicule in HF over time. Micrographs were taken after $5 \mathrm{~min}$ (a), $12 \mathrm{~min}$ (b), $20 \mathrm{~min}$ (c), and $40 \mathrm{~min}$ (d). The HF solution was supplemented with Coomassie Brilliant Blue to visualize the proteins. Residual collagen $(\mathrm{col})$ partially surrounding the spicules was immediately stained. The axial filament could be visualized with this stain $(5-15 \mathrm{~min})$, until finally the proteinaceous tube $(t u)$ was released in addition to the axial filament (af)

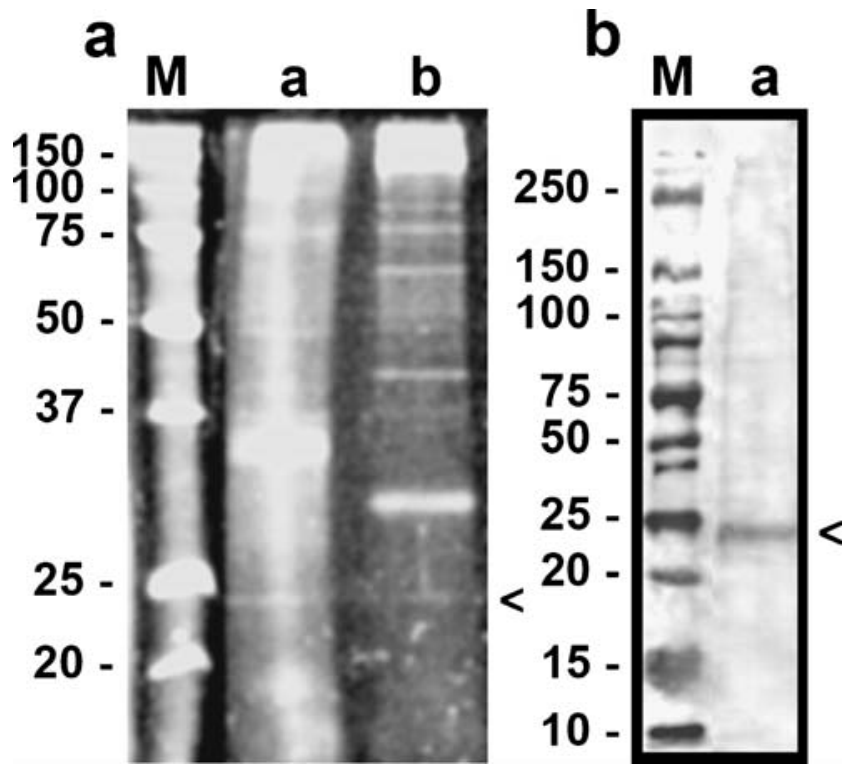

Fig. 8 SDS-PAGE and Western blot analysis of proteins isolated from giant basal spicules after HF treatment ( $M$ size marker). a Extracts were separated by SDS-PAGE (10\% polyacrylamide/0.1\% SDS). Untreated (lane $a$ ) and deglycosylated (lane $b$ ) preparations were sizeseparated. After separation on the gels, the polypeptides were visualized with Sypro Ruby protein gel stain. b Western blot analysis of proteins in the extracts from spicules not treated with glycosidases. The proteins were subjected to SDS-PAGE (12\% polyacrylamide/ $0.1 \%$ SDS) and electrophoresed. After blot transfer, the proteins were reacted with anti-silicatein polyclonal antibodies. Immunocomplexes (arrowhead) were visualized with an alkaline-phosphatase-labeled secondary antibody (lane a)

protein band was seen for the $35-\mathrm{kDa}$ polypeptide band (prior to deglycosylation), which showed an apparent size of $30 \mathrm{kDa}$ after deglycosylation (Fig. 8a; lane b). After this treatment, the 24-kDa polypeptide remained in the preparation (Fig. 8a; lane b).

In order to obtain a first indication of whether silicatein was present in the native preparation from spicules of $M$. chuni, the proteins were subjected, after SDS-PAGE, to Western blot analysis. After blot transfer, the proteins were reacted with PoAb-aSilic and subsequently with an alkaline-phosphatase-labeled secondary antibody. After this procedure, a clear band corresponding to $24 \mathrm{kDa}$ became visible (Fig. 8b; lane a). This polypeptide did not react with PoAb-aSilic that had been pre-treated with recombinant silicatein (control; not shown).

Proteolytic activity in spicular extracts

Proteins were released from spicules and analyzed for protease activity by zymogram analysis. After size-separation, the gelatin-containing gels were incubated to detect proteolytic activity by staining the gel in Coomassie Brilliant Blue. Clear bands developed after the separation of $M$. chuni extracts and had sizes of $130 \mathrm{kDa}, 100 \mathrm{kDa}$, and $70 \mathrm{kDa}$ (Fig. 9; lane a, lane b). Smaller peptides 


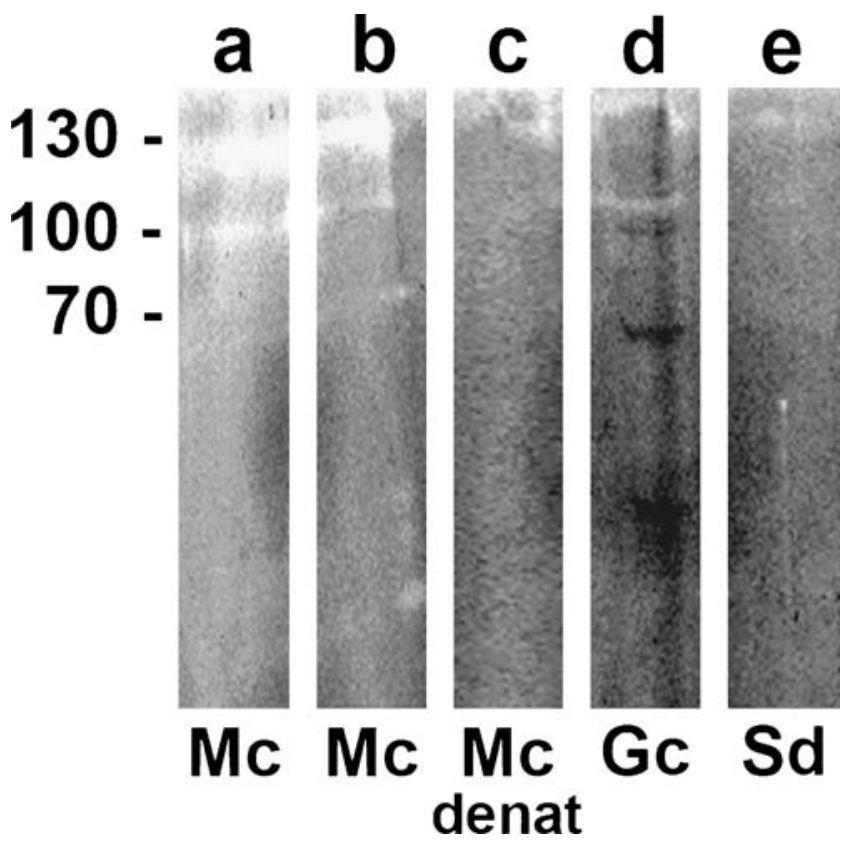

Fig. 9 Proteolytic activity in protein extracts from spicules. Spicular extracts from $M$. chuni (lane $a$ corresponding to a protein extract from about $400 \mu \mathrm{g}$ spicules, lane $b$ corresponding to a protein extract from about $200 \mu \mathrm{g}$ spicules) were analyzed. Denatured extract $\left(95^{\circ} \mathrm{C}\right.$, $5 \mathrm{~min})$ from $M$. chuni $(400 \mu \mathrm{g})$ was also examined (lane $c$ ). In parallel, extracts from $G$. cydonium (lane $d ; 400 \mu \mathrm{g}$ ) and $S$. domuncula (lane e; $400 \mu \mathrm{g}$ ) were additionally tested

$(<40 \mathrm{kDa})$ did not show any activity. In order to determine whether the bands visualized after staining were attributable to proteolytic degradation, the sample was denatured at $95^{\circ} \mathrm{C}$; no band could be visualized after this treatment (Fig. 9; lane c). In a comparative analysis, extracts of spicules from the Demospongiae, G. cydonium (Fig. 9; lane d) and $S$. domuncula (Fig. 9; lane e) were also analyzed. Interestingly, the bands reflecting proteolytic activity (with a size of $130 \mathrm{kDa}$ and $100 \mathrm{kDa}$ ) also appeared.

\section{Cloning of cDNA for collagen from an hexactinellid}

The complete collagen cDNA was obtained from Aphrocallistes vastus by using the described PCR approach. The 2610-nt-long sequence APHVACOL comprises one open reading frame from $\mathrm{nt}_{43-45}$ to $\mathrm{nt}_{2351-2353 \text { (stop). The deduced }}$ polypeptide (termed COL_APHRO) comprises 784 aa with a predicted size of $74,786 \mathrm{Da}$ and an isoelectric point of 4.2 (Fig. 10a). Like the related mammalian collagen sequences, the sponge protein comprises 585 long collagen triplet (G$\mathrm{x}-\mathrm{x})$ repeats. The predicted collagen is a soluble protein and possesses no pronounced hydrophobic region (average hydrophobicity: -0.849745 ) according to the secondary structures prediction (Rao and Argos 1986).

The highest similarity score of the $A$. vastus collagen was determined with the type IV collagen alpha 1 chain precursor from Hydra vulgaris, showing a "expect value" (Coligan et al. 1998) of $4 \times \mathrm{e}^{-42}$. Similar high scores existed for other metazoan collagen sequences. For the phylogenetic analysis, the sequences with the highest similarities to the A. vastus collagen were selected not only from Hydra, but also from human (alpha 1 chain-like collagen precursor), Drosophila melanogaster (collagen type IV), Caenorhabditis elegans (collagen alpha-2 chain precursor), and the two $S$. domuncula sequences (collagen 1 and collagen2; Fig. 10b). No collagen sequences were identified in non-metazoan organisms. After alignment of these sequences, the slanted tree was constructed and rooted with the A. vastus sequence as the outgroup. The Hydra sequence fell into one branch, together with the collagens from the protostomians D. melanogaster and C. elegans, whereas the two collagens from $S$. domuncula clustered together with the human sequence (Fig. 10b).

\section{Discussion}

At present, the marine environment is relatively poor in silicon concentration, ranging from $3 \mu \mathrm{M}$ at the surface to $180 \mu \mathrm{M}$ in deep water (Maldonado et al. 1999). However, sponges are provided, as has been shown in the siliceous demosponge $S$. domuncula, with a transporter system for silica uptake; this probably involves a $\mathrm{Na}^{+} / \mathrm{HCO}_{3}{ }^{-}[\mathrm{Si}$ $\left.(\mathrm{OH})_{4}\right]$ (NBCSA) cotransporter (Schröder et al. 2004a). The higher concentration of silicon/silica in the deep sea can be postulated as facilitating and allowing the formation of giant siliceous sponges, with the 3-m-high M. chuni being a good example. The major skeletal elements of these sponges are the giant basal spicules that reach a size of $3 \mathrm{~m}$ and a diameter of up to $7 \mathrm{~mm}$ (see above). These large spicules might allow the animals to maintain a siutable distance from the muddy ground on which they live (Schulze 1904). Stony corals are sometimes found on these spicules (Schulze 1904) suggesting a mutualistic (at least) symbiotic relationship. Recent molecular biological studies have revealed that the siliceous demosponges are provided with the genetic "toolkit" to construct these skeletal elements, the spicules, functional animals being composed of differentiated cells that interact in a tissue-like manner and that allow the formation of a body plan (Müller et al. 2004; Müller 2005; Pilcher 2005). M. chuni is a siliceous sponge, belonging to the phylogenetically oldest Poriferan class, the Hexactinellida (Kruse et al. 1997).

The structure of hexactinellidan spicules has previously been studied to some considerable detail, most notably by Schulze (1904) and Schmidt (1926) who, in the early literature, reported the lamellar organization of the silica layers of the spicules; these layers have been assumed to be separated from each other by organic components (Schmidt 1928). Levi et al. (1989) have demonstrated that this lamellar organization contributes significantly to the stabi- 
a

COL_APHRO --MSTLVDPKNSARDGPQGPEGPKGARGNEGSSGLQGDKGDTGLPGGIGLPGPSGLGGNDGTVGDSGDQGEAGLKGDKGQGDQG 83 COL 4 _HYDRA GEQGKKGDQGQKGEPGQPGQAGEAGQDGQKGEKGDKGEIGSAGPSGIQGEKGDIGATGAAGTKGEPGSDGSLGSPGQKGDHGTKG 340

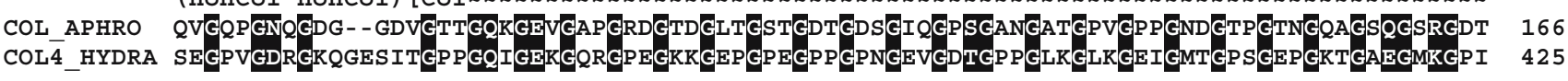

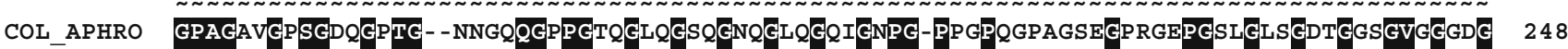
COL $\overline{4}$ _HYDRA GPAGQREETGSKGESGRPGQSVQGSPGMDGNPGQIGPPGEPGIPGFPGPPGNPGQVVNDLEETVLPGPPGDQGPQGIQGVAGPQG 510 COL_APHRO EKGEKGSTGIGGSEGPPGEQGQIGDSGATGSDGPAGPAGGFGVQGASEDQGNQGETGPAGRDGNPGQNGNSGPPGDACVDGVNGE 333

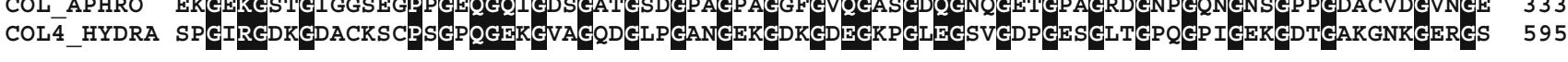

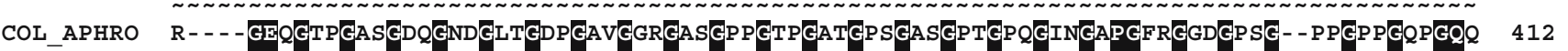
COL4_HYDRA DRIVQGERGEKGTDGMPGSPGSIGFKGEQGVPGDPGTDGPQGPQGLQGPQGDRGAPGKSEIPGNNGEKGEKGNKGDGLRGFKGER 680

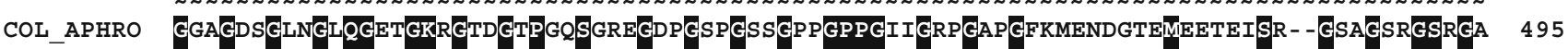
COL4_HYDRA GRDGEPGPKGSQGPMGKPGPKGEPFSTALKGQQGDKGDVGSEGPPGPQGAEGQVGNQGFKGEPGLRGAPGSGEKGEKGDAGTPGI 765

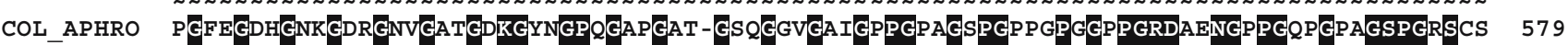
COL 4 HYDRA AGKNGENGKDGQDGPKGDKGEKGLQGPIGISGPIKGEPGLKGDPGKPGLDGAPGKSVPKGEPGRDGKDGDPGAKGEPGTPGESGR 850

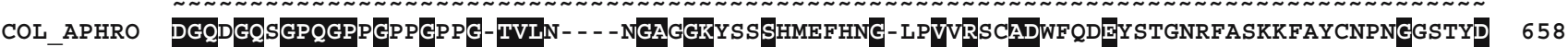
COL 4 _HYDRA DGEKGEIGPQGPQGDKGDQGQSVIGPKGETGAIGKKGETGQDGLKGRDGIGKQGANGEKGEKGNSVVGLPGDPGEKGSPGEKGKD 935

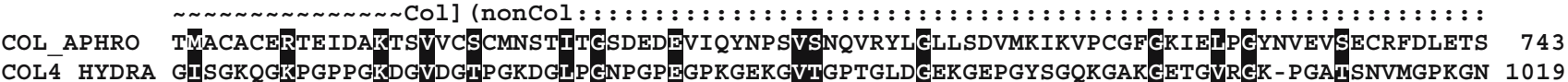
COL 4 HYDRA GISGKQGKPGPPGKDGVDGTPGKDGLPGNPGPEGPKGEKGVTGPTGLDGEKGEPGYSGQKGAKGETGVRGK-PGATSNVMGPKGN
: : : : : : : : : : : : : : : : : : : : : : : : : : : : : : : : : : : : : : : : : : : : : : : : : : : : : : : : : : : : : : : : : : : : : : : : : COL_APHRO VQEILLQPEFLQTKLPIASFPSSYSLNARNEVCFGVRMSQK COL4_HYDRA RGESGAKGEPGKQGPPGAEGPQGEKGERGIGTDKGTKGDTGDIGLQGPKGERGERGEQGRKGDQGPIGPKGDVGEPGPAGSIGNT 1104 : : : : : : : : : : : : : : : : : : : : : : : : : : : : : : : : : : :nonCol)

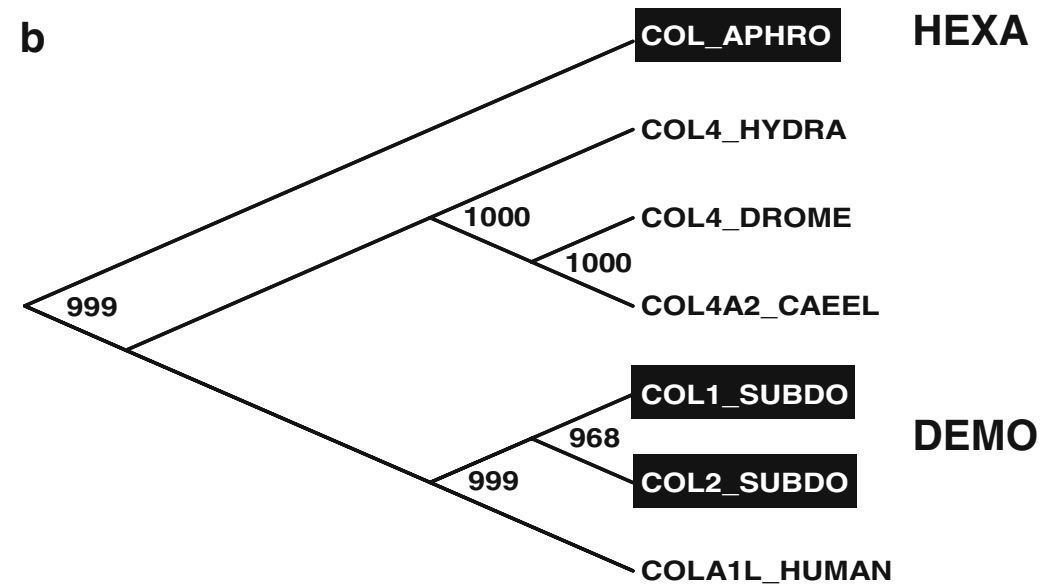

Fig. 10 a Collagen from the hexactinellid A. vastus (COL_APHRO). This deduced protein was aligned with the related sequence from Hydra vulgaris, the type IV collagen alpha 1 chain precursor (COL4_HYDRA; accession number AAG40729, Fowler et al. 2000; the sequence had been truncated at the $\mathrm{C}$-terminus after aa 1,104). The region comprising the typical collagen triplets $(\mathrm{G}-\mathrm{x}-\mathrm{x})$ is marked $(\mathrm{Col})$; the flanking non-collagen regions are also delimited (nonCol). Residues conserved (identical or similar with respect to their physicochemical properties) in the sequences are shown in white on black. b The Hydra and A. vastus proteins were compared with the related molecules from human (alpha 1 chain-like collagen COLA1L precursor:

lization of the giant basal spicules of Monorhaphis. Only recently successful attempts have been performed to clarify, from a structural biological point of view, the formation of spicules in the hexactinellid Euplectella (Aizenberg et al. 2005). Ehrlich et al. (2005) obtained the first indications
COLA1L-HUMAN; AAL50033), Drosophila melanogaster (collagen type IV; COL4_DROME; NP_723044), Caenorhabditis elegans (collagen alpha-2(IV) chain precursor: COL4A2 CAEEL; P17140), and Suberites domuncula (collagen1: COL1_SUBDO; CAJ43111, Schröder et al. 2006; collagen2: COL2_SUBDO; CAC03736, Krasko et al. 2000). The slanted tree was constructed and rooted with the A.vastus sequence as an outgroup. Numbers at nodes are an indication of the level of confidence (given in percent) for the branches as determined by a bootstrap analysis (1000 bootstrap replicates; HEXA hexactinellid sponge, $D E M O$ demosponges)

that collagen contributes to the formation of hexactinellidan spicules. In the present study, we have investigated the morphology and formation of the spicules from M. chuni, mainly focusing on the large comitalia and the giant basal spicules. 
The lamellar organization, both of the smaller (choanosomal) spicules and the larger comitalia and giant basal spicules, have been studied by using 100-year-old samples and recent spicules. In these two types of spicules, the size of the lamellae is approximately $5 \mu \mathrm{m}$ in width. The lamellae are separated from each other by a gap that shows, in the more central regions, no continuum but concentrically arranged holes separated by silica bridges, allowing the lamellae to fuse. These silica bridges have been seen in all spicules analyzed, strongly suggesting that they are not formed secondarily. In the central core of the spicule, the lamellae are fused together appearing as a solid silica cylinder, a pattern that is especially pronounced in the giant basal spicules. This cylinder/canal harbors the axial canal with its axial filament. As shown in this study, the immature growing spicules exhibit a rectangular axial canal, suggesting a similar shape for the axial filaments. This form of the canal suggests that the filamentous proteins in $M$. chuni are arranged in a tetragonal pattern. A hexagonal organization of the silicatein in the axial filaments has been demonstrated in the demosponge $G$. cydonium (Croce et al. 2004). However, detailed studies of hexactinellids are lacking. We have adopted the view of Schulze (1904), namely that the central cylinder, which reaches a width of 100-150 $\mu \mathrm{m}$ is also initially synthesized in a lamellar manner and not as a solid stalk, taking into account that the enzymatic synthesis of the lamellae in Demospongiae never exceeds a width of $20 \mu \mathrm{m}$. The axial filament in the spicules can, with time and growth of the spicules, become thinner, as has long been known (Schmidt 1926). The number of lamellae in the giant basal spicules of M. chuni can attain 400-600. The thickness of the lamellae within the spicules in $M$. chuni varies between 3 and $10 \mu \mathrm{m}$. The axial canals in growing spicules from M. chuni are larger $(3$ to $5 \mu \mathrm{m})$ than those found in completed spicules, as previously mentioned by Schulze (1904). In the spicules, the canal can even disappear and become filled with silica (Schulze 1904). The major reason for studying the structure of the spicules here has been to understand the growth pattern of the spicules in an axial and radial direction. All (or almost all) spicules of M. chuni are open at their tips (Schulze 1904; Uriz 2006; Uriz et al. 2003); their axial canals occasionally expose the axial filaments. This finding has contributed to the understanding of the axial growth of the spicules (see below). The data available indicate that all spicules in Hexactinellida possess an axial filament (Uriz 2006).

The initial chemical composition of hexactinellidan spicules was provided by Schulze (1904), who found that, other than $\mathrm{Si}(96 \%)$, only $\mathrm{Na}$ and $\mathrm{K}$ contribute to the inorganic material in measurable amounts. This composition was later confirmed by Levi et al. (1989) and Sandford (2003). In the analytical data, presented here, Si has been shown to be uniformly distributed throughout the silica shell of the spicules, whereas $\mathrm{Na}$ and $\mathrm{K}$ are not. Higher levels of $\mathrm{K}$ have been measured (around $1 \mathrm{wt} \%$ ) in the central part of the spicules, whereas the amount drops considerably $(\approx 0.4 \mathrm{wt} \%)$ at the surface. The inverse is true of the distribution of Na; here, the level is almost negligible at the center $(\approx 0.03 \mathrm{wt} \%$ ) but increases toward the surface to $\approx 0.4 \mathrm{wt} \%$. One explanation might be that the much higher concentration of $\mathrm{Na}$ than $\mathrm{K}$ in seawater (Kennish 1994) causes an exchange to occur with respect to the initially synthesized $\mathrm{K}^{+}$-silicate to $\mathrm{Na}^{+}$-silicate, after exposure of the siliceous spicules to the surrounding milieu. However, another explanation might also be possible: Iler (1979) and Perry (2003) have demonstrated that, in the presence of smaller cations (e.g., $\mathrm{Na}^{+}$), a faster condensation rate of silica occurs, in comparison with the rate measured with larger cations (e.g., $\mathrm{K}^{+}$). This view is supported by studies with diatoms in which $\mathrm{Si}$ transport into cells has been proposed to be driven by $\mathrm{Na}^{+}$-gradients generated and maintained across the membrane by the activity of a $\mathrm{Na}^{+} / \mathrm{K}^{+}$-ATPase (Sullivan 1986). In sponges, with $S$. domuncula as a model, data have been presented that are compatible with the view that silica uptake is mediated by an NBCSA cotransporter. If this assumption reflects the physiological situation, then $\mathrm{Na}^{+}$-silicate condensation products would first be formed at the sites of synthesis of the spicules during the appositional layering of silica lamella that occurs on the outer surface of the spicules and would be converted to $\mathrm{K}^{+}$-silicate containing oligo- and polymers. This argument is sustained by results of a previous study: (1) in other preparations from M. chuni (Levi et al. 1989), an overall high concentration of sodium exists in these spicules (approximately $50 \%$ of the concentration determined for potassium), and (2) an apparent uniform distribution of these two ions occurs throughout the spicules (Levi et al. 1989). The zonation of lamellae with different mechanical properties has been proposed by Schulze (1904) and Schmidt (1926) and, more recently, by Levi et al. (1989). However, no data concerning the water content or the hardness of the various layers have existed until now. The differential chemical composition within the spicules, as described here, can be considered as a first step toward an understanding of their mechanical properties. Additionally, we have performed spectroscopical analysis to identify water in the amorphous silica (not shown here) and have confirmed the previous data of Levi et al. (1989), indicating that M. chuni spicules contain between $5 \%$ and $10 \%$ water in combination with silicate.

In all Demospongiae, the formation of the spicules starts from the axial canal, followed by an appositional layering of the silica lamellae (Schröder et al. 2006). Two methods have been employed to localize the protein(s) within the spicules of M. chuni; first, by dissolution with HF and 
simultaneous staining with Coomassie Brilliant Blue, and second, by biochemical techniques. Until now, (almost) no biochemical data has been available with regard to the spicules of hexactinellidan sponges. Here, we show, by a stepwise dissolution of the siliceous lamella from the spicules, that the axial filament is released. The dissolution of the silica shell around the axial filament does not occur uniformly, but rather in a zigzag manner apparently along the slits between two lamellae. We have also demonstrated that, after exposure of the axial filament and following completion of the dissolution of the inorganic material, a proteinaceous tube remains that has the diameter of the outer surface of the spicules. Since no evidence from electron-microscopic images has been obtained concerning the existence of a continuous protein layer within the inner layers of the spicules, we assume that this tube represents the matrix of the silicification process of the outer lamellae. In previous studies, proteinaceous filaments have been assumed to traverse the lamellae (see Schmidt 1926). However, all our electron-microscopic studies and the light-microscopic images favor the view that, other than the inner axial filament, the organic material of the spicules is concentrated in the proteinaceous tube surrounding the external surface of the spicules. Hence, no structural bundles are expected to be located within these silica lamellae.

After complete dissolution of the silica shell of the giant basal spicule by HF, the residual protein "shell" was analyzed by SDS-PAGE. The results were informative in several aspects. First, two dominant protein molecules could be identified, having a size of $150 \mathrm{kDa}$ and $35 \mathrm{kDa}$. In previous studies with Demospongiae, no high-molecularweight protein could be obtained after dissolution with HF (Schröder et al. 2004b); high-molecular-weight polypeptides of $250 \mathrm{kDa}$ could only be identified after a less harsh release of the proteins from the spicules, viz., by mechanical grinding and urea extraction (Schröder et al. 2006). No data on the function of this large protein $(250 \mathrm{kDa})$ exist. The $35-\mathrm{kDa}$ protein species identified in $M$. chuni is likewise present in $S$. domuncula; in the latter demosponge, this protein is a galectin. Recent studies with $M$. chuni extracts have revealed the presence of a lectin (data not shown here). This $35-\mathrm{kDa}$ protein has been identified as a glycoprotein that, after deglycosylation, migrates as a molecules of $30 \mathrm{kDa}$. This is the first published data regarding the participation of glycoproteins in the construction/synthesis of siliceous spicules. As a result of this finding, parallel experiments have been performed with $S$. domuncula spicules and have likewise revealed the existence of glycoproteins (to be published). Finally, one protein species with a molecular weight of $24 \mathrm{kDa}$ should be mentioned because, on the basis of its size, it might be silicatein (Schröder et al. 2004b, 2006). Application of antibodies raised against $S$. domuncula silicatein has shown cross-reactivity to the $24-\mathrm{kDa} M$. chuni protein. This finding could be taken as the first evidence for the existence of silicatein (or of a silicatein-related protein) in Hexactinellida.

In a recent study, a model for the appositional growth of the spicules from Demospongiae has been proposed that suggests the involvement of silicatein and additional proteins, e.g., galectin, which might mediate silica deposition in a centrifugal and centripetal direction (Schröder et al. 2006). This implies the existence of a protease that lies within the residual organic matrix in the spicules and that dissolves the included proteins over time. In order to test this assumption, we have perfomed zymogram analysis with extracts from $M$. chuni spicules. In our preparations, proteases with sizes of $130 \mathrm{kDa}, 100 \mathrm{kDa}$, and $70 \mathrm{kDa}$ have been identified. Their activities are abolished by heating the samples, thus underscoring the proteinaceous origin of the activity. In subsequent parallel studies based on size, similar proteases have also been identified in the two Demospongiae, S. domuncula and G. cydonium. At present, we hypothesize that the protease, existing within the spicules, is involved in the hydrolytic cleavage of the proteinaceous inner organic layer of the cylinder, after completion of the silica lamella.

Our analytical data, such as the presence of the major molecules known from demosponge spicules, e.g., the highmolecular-weight proteins, the $35 \mathrm{kDa}$ protein representing a lectin, the proteases, and silicatein or a silicatein-like molecule, suggest a high degree of parallelism in the protein pattern and function between Demospongiae and Hexactinellida. In a final functional study, we tested whether the proteins isolated from M. chuni also displayed silicatein activity. The same assay system that had been applied previously (Cha et al. 1999; Krasko et al. 2000; Kaluzhnaya et al. 2005a, b), with the alkoxy compound TEOS, gave no indication for the presence of active silicatein molecules in M. chuni. This might indicate that no silicatein or silicatein-like proteins exist in this hexactinellid, or that such a molecule becomes functionally inactivated during the HF-dissolution process. In future studies, a less harsh dissolution procedure will be applied for the extraction of proteins from spicules of $M$. chuni to trace silica-synthesizing activity in this taxon.

Until now, only a working model for the synthesis of the M. chuni spicules has been proposed. Electron-microscopic studies have revealed that the tips of the spicules from this hexactinellid can be distinguished from those found in Demospongiae (Uriz et al. 2003), since all of them are open (Schulze 1904). The images show that the characteristic quadratic opening, viz., the axial canal, occasionally possesses an axial filament that reaches the upper edges of the top orifice. Taking previous data (Schulze 1904; Aizenberg et al. 2005) and the results presented here 
together, we consider that the spicules of Hexactinellida have been established to grow in a lamellar manner. Moreover, in view of the similarity of their structural protein pattern and their potential function, silicatein (or a silicatein-related protein) is unlikely to become associated with the surface of the spicules (Fig. 5b-1,b-2). With the longitudinal growth of the spicules, the protein mediates the silica deposition (Fig. 5b-3,b-4) and finally becomes internalized through the apical opening and associated with the axial filament (Fig. 5b-5). However, a final answer can only be given after the cloning and expression of the putative silicatein molecules in Hexactinellida.

The spicules are surrounded by collagen mats that leaves open holes with a diameter of $7-10 \mu \mathrm{m}$. This pattern of collagen cover around the spicules has previously been noticed by Schulze (1904) and attributed to the characteristic synthesis by the spicule-associated cells and their fixation in the mesohyl (the interior tissue with its bulky extracellular material). Until now, evidence has been lacking that these collagen fibrils are covered by silica. The morphology of the collagen fibrils in $M$. chuni is not common in other studied siliceous sponges (Garrone 1984). In this hexactinellid, the collagen fibrils have a pearl-stringlike appearance, whereas in Demospongiae, the collagen takes the form of plain rods. The fibrils tightly surround the spicules and might be involved in the shaping of the form of the spicules. In addition, they are, as shown here, also involved in the association of the spicules among each other. This conclusion is drawn from the images of samples of tauactins and comitalia stained with Sirius Red for collagen.

To date, collagen molecules had only been described in Demospongiae (see Garrone 1998). Therefore, we screened a cDNA library from the hexactinellid $A$. vastus for the existence of collagen transcripts. One sequence was identified, and its deduced polypeptide was found to be highly related to the collagen alpha 1 chain precursor from $H$. vulgaris. The $A$. vastus protein comprises a 585 -aa-long stretch comprising the characteristic collagen triplet repeats. As also known from other demosponge collagens, this hexactinellid-deduced protein frames the collagen triplets by non-collagen repeats.

Having substantiated the existence of collagen in spicules, we can present an overall schematic outline of spicule formation in M. chuni with its lamellar biosilica organization (Fig. 11). In the center of the spicules, the axial canal is filled with an axial filament that has a protein composition highly similar to that described for demosponges. After the formation of the first silica layer (assumed to involve silicatein or a silicatein-related protein), the next layer is formed through the centrifugal and centripetal synthesis of silicatein(-related) protein. By analogy to the Demospongiae (Schröder et al. 2006), the silicatein(-related) protein is assumed to associate with a lectin that forms a tube-like cage around the existing silica lamella. After deposition of newly formed silica clusters
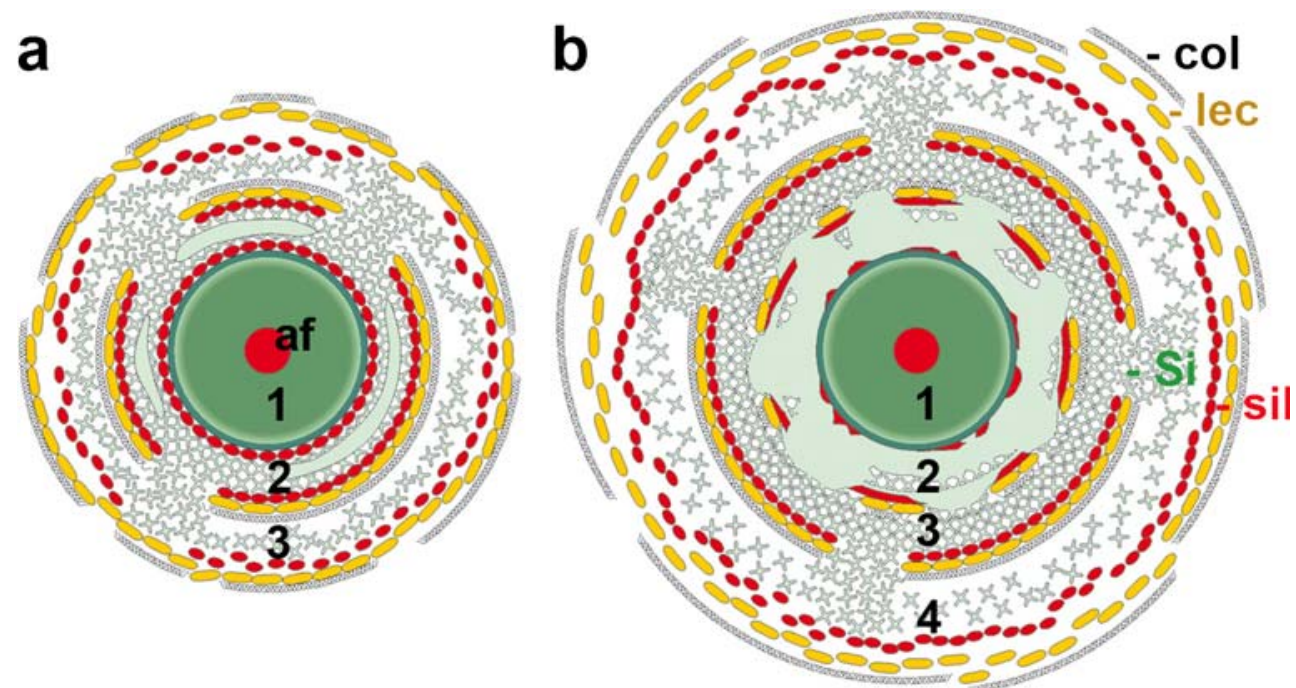

Fig. 11 Proposed method of formation of spicules in the hexactinellid M. chuni by appositional lamellar growth. The center of the spicule comprises an axial canal filled with an axial filament (af, red); the protein composition includes also the silicatein(-related) protein. Around the axial filament, the first lamella has been formed (1). The formation of the next silica lamella is thought to be mediated by silicatein(-related) proteins (red ellipsoid dots) arranged on both the surface of the first lamella and on a proteinaceous tube/cage stabilized in its outer layer by lectin molecules (yellow dots). The final

orientation of the tube is provided by the collagen mat. Within the cage, a solid silica lamella is formed through an association of the silica clusters (left to right). During this growth process of the spicules, a thickening of the spicules takes place by the formation of new silica lamellae $(2-4)$. The organic material of the cage undergoes proteolytic disintegration, as indicated in layers 2 and 3 . The concentric arrangement of the silicatein(-related) proteins/lectin associates is proposed to be stabilized by collagen (gray fibers) 
followed by a solid silica lamella, the existing proteins are hydrolyzed by protease(s). In continuation, a third lamella of silica is formed. This dynamic model (Fig. 11) also proposes that collagen guides the silicatein(-related) protein/lectin associates concentrically along the spicules. Recently, we have identified extracellular vesicles that are filled with silicon and that we term silicasomes in the tissue of demosponge (W.E.G. Müller, in preparation). In view of these findings, we postulate that silicon/silicic acid is released by the cells, compartmentalized into vesicles, and channeled into the tube-like cage into which the silica lamellae are formed.

Now that these structural and morphological data concerning the spicules of $M$. chuni have been obtained, the next steps will be the identification of the genes encoding the respective proteins in order to obtain the recombinant proteins and then the antibodies for light- and immuno-electron-microscopic studies. These methods should finally result in a unequivocal identification of the proteins and their functions in the synthesis of hexactinellidan spicules; such strategies have recently been successfully applied to the demosponge $S$. domuncula (Müller et al. 2006; Schröder et al. 2006).

Acknowledgement We thank Ms. E. Sehn (Zoological Institute, University of Mainz, Germany) for valuable technical assistance. Material was provided by Dr. D. Bernhard (Zoological Institute, University of Leipzig, Germany), Dr. C. Lüter (Museum für Naturkunde, Berlin, Germany), Prof. Dr. R. Kinzelbach (Zoological Institute, University of Rostock, Germany), and Dr. K. Tabachnick (Institute of Oceanology, Moscow, Russia).

\section{References}

Aizenberg J, Weaver JC, Thanawala MS, Sundar VC, Morse DE, Fratzel P (2005) Skeleton of Euplectella sp.: structural hierarchy from nanoscale to the macroscale. Science 309:275-278

Cha JN, Shimizu K, Zhou Y, Christianssen SC, Chmelka BF, Stucky GD, Morse DE (1999) Silicatein filaments and subunits from a marine sponge direct the polymerization of silica and silicones in vitro. Proc Natl Acad Sci USA 96:361-365

Chun C (1900) Aus den Tiefen des Weltmeeres. Fischer, Jena

Coligan JE, Dunn BM, Speicher DW, Wingfield PT (1998) Current protocols in protein science. Wiley, New York, pp 10.4.1-10.4.36

Compton S, Jones C (1985) Mechanism of dye response and interference in the Bradford protein assay. Anal Biochem 151:369-374

Corsetti FA, Olcott AN, Bakermans C (2006) The biotic response to the Neoproterozoic snowball Earth. Palaeogeogr Palaeoclimatol Palaeoecol 232:114-130

Croce G, Frache A, Milanesio M, Marchese L, Causa M, Viterbo D, Barbaglia A, Bolis V, Bavestrello G, Cerrano C, Benatti U, Pozzolini M, Giovine M, Amenitsch H (2004) Structural characterization of siliceous spicules from marine sponges. Biophys J 86:526-534

Dayhoff MO, Schwartz RM, Orcutt BC (1978) A model of evolutionary change in protein. In: Dayhoff MO (ed) Atlas of protein sequence and structure. National Biomedical Research Foundation, Washington, DC, pp 345-352

Eckert C, Schröder HC, Brandt D, Perovic-Ottstadt S, Müller WEG (2006) A histochemical and electron microscopic analysis of the spiculogenesis in the demosponge Suberites domuncula. J Histochem Cytochem 54:1031-1040

Ehrlich H, Hanke T, Simon P, Goebel C, Heinmann S, Born R, Worch $\mathrm{H}$ (2005) Demineralisation von natürlichen Silikat-basierten Biomaterialien: neue Strategie zur Isolation organischer Gerüststrukturen. Biomaterialien 6:297-302

Felsenstein J (1993) PHYLIP, ver. 3.5. University of Washington, Seattle

Fowler SJ, Jose S, Zhang X, Deutzmann R, Sarras MP, Boot-Handford RP (2000) Characterization of hydra type IV collagen. Type IV collagen is essential for head regeneration and its expression is up-regulated upon exposure to glucose. J Biol Chem 275:3958939599

Garrone R (1984) Formation and involvement of extracellular matrix in the development of sponges, a primitive multicellular system. In: Trelstad RL (ed) The role of extracellular matrix in development. Liss, New York, pp 461-477

Garrone R (1998) Evolution of metazoan collagens. Prog Mol Subcell Biol 21:139-191

Gundacker D, Leys SP, Schröder HC, Müller IM, Müller WEG (2001) Isolation and cloning of a C-type lectin from the hexactinellid sponge Aphrocallistes vastus: a putative aggregation factor. Glycobiology 11:21-29

Holmes RE, Hagler HK, Coletta CA (1987) Thick-section histometry of porous hydroxyapatite implants using backscattered electron imaging. J Biomed Mat Res 21:731-738

Iler RK (1979) The chemistry of silica. Wiley, New York

Jaffe CL, Dwyer DM (2003) Extracellular release of the surface metalloprotease, gp63, from Leishmania and insect trypanosomatids. Parasitol Res 91:229-237

Junqueira LCU, Bignolas G, Brentani RR (1979) Picrosirius staining plus polarization microscopy, a specific method for collagen deterction in tissue sections. Histochem J 11:447-455

Kaluzhnaya OV, Belikov SI, Schröder HC, Rothenberger M, Zapf S, Kaandorp JA, Borejko A, Müller IM, Müller WEG (2005a) Dynamics of skeletal formation in the Lake Baikal sponge Lubomirskia baicalensis. I. Biological and biochemical studies. Naturwissenschaften 92:128-133

Kaluzhnaya OV, Belikov SI, Schröder HC, Rothenberger M, Zapf S, Kaandorp JA, Borejko A, Müller IM, Müller WEG (2005b) Dynamics of skeletal formation in the Lake Baikal sponge Lubomirskia baicalensis. II. Molecular biological studies. Naturwissenschaften 92:134-138

Kennish MJ (1994) Practical handbook of marine science. CRC Press, Boca Raton

Krasko A, Batel R, Schröder HC, Müller IM, Müller WEG (2000) Expression of silicatein and collagen genes in the marine sponge Suberites domuncula is controlled by silicate and myotrophin. Eur J Biochem 267:4878-4887

Kruse M, Müller IM, Müller WEG (1997) Early evolution of metazoan serine/threonine- and tyrosine kinases: identification of selected kinases in marine sponges. Mol Biol Evol 14:1326-1334

Levi C, Barton JL, Guillemet C, Le Bras E, Lehuede P (1989) A remarkably strong natural glassy rod: the anchoring spicule of the Monorhaphis sponge. J Mater Sci Lett 8:337-339

Li J (1987) Monorhaphis intermedia - a new species of Hexactinellida. Oceanol Limnol Sinica 18:135-137

Maldonado M, Carmona NC, Uriz MJ, Cruzado A (1999) Decline in Mesozoic reef-building sponges explained by silicon limitation. Nature 401:785-788

Müller WEG (2005) Spatial and temporal expression patterns in animals. In: Meyers RA (ed) Encyclopedia of molecular cell 
biology and molecular medicine, vol 13. Wiley-VCH, Weinheim, pp 269-309

Müller WEG, Krasko A, Le Pennec G, Steffen R, Ammar MSA, Wiens M, Müller IM, Schröder HC (2003) Molecular mechanism of spicule formation in the demosponge Suberites domuncula: silicatein-collagen-myotrophin. Prog Mol Subcell Biol 33:195-221

Müller WEG, Wiens M, Adell T, Gamulin V, Schröder HC, Müller IM (2004) The Bauplan of the Urmetazoa: the basis of the genetic complexity of Metazoa using the siliceous sponges [Porifera] as living fossils. Int Rev Cytol 235:53-92

Müller WEG, Rothenberger M, Boreiko A, Tremel W, Reiber A, Schröder HC (2005) Formation of siliceous spicules in the marine demosponge Suberites domuncula. Cell Tissue Res 321:285-297

Müller WEG, Belikov SI, Tremel W, Perry CC, Gieskes WWC, Boreiko A, Schröder HC (2006) Siliceous spicules in marine demosponges (example Suberites domuncula). Micron 37:107-120

Nicholas KB, Nicholas HB Jr (1997) GeneDoc: a tool for editing and annotating multiple sequence alignments. Version 1.1.004 (distributed by the author; cris.com/ ketchup/genedoc.shtml)

Perry CC (2003) Silicification: the process by which organisms capture and mineralize silica. Rev Mineral Geochem 54:291-327

Pilcher H (2005) Back to our roots. Nature 435:1022-1023

Rao J, Argos P (1986) A conformational preference parameter to predict helices in integral membrane proteins. Biochem Biophys Acta 869:197-214

Reiswig HM (2006) Classification and phylogeny of Hexactinellida (Porifera). Can J Zool 84:195-204

Reitner J, Wörheide G (2002) Non-lithistid Demospongiae apsorigins of their palaeobiodiversity and highlights in history of preservation. In: Hooper JNA, Van Soest RWM (eds) Systema porifera: a guide to the classification of sponges. Kluwer Academic/Plenum, New York, pp 52-70

Roux M, Bouchet P, Bourseau JP, Gaillard C, Grandperrin R, Guille A, Laurin B, Monniot C, Richer de Forges B, Rio M, Segonzac M, Vacelet J, Zibrowius H (1991) L'environment bathyal au large de la Nouvelle-Calédonie: résultats preliminaries de la campagne CALSUB et consequences paléoécologiques. Bull Soc Geol France 162:675-685

Sandford F (2003) Physical and chemical analysis of the siliceous skeleton in six sponges of two groups (Demospongiae and Hexactinellida). Microsc Res Tech 62:336-355

Schmidt WJ (1926) Über das Wesen der Lamellierung und das gegenseitige Verhalten von organischer und anorganischer Substanz bei den Kieselschwammnadeln. Zool Jahrb (Abt Morphol) 48:311-364

Schmidt WJ (1928) Die Pfahlnadel von Monorhaphis chuni F.E. Schulze. Mikrokosmos 21:113-120

Schrammen A (1924) Die Kieselspongien der oberen Kreide von Nordwestdeutschland. Monogr Geol Paleontol 2:1-159

Schröder HC, Perović-Ottstadt S, Rothenberger M, Wiens M, Schwertner H, Batel R, Korzhev M, Müller IM, Müller WE (2004a) Silica transport in the demosponge Suberites domuncula: fluorescence emission analysis using the PDMPO probe and cloning of a potential transporter. Biochem J 381:665-673

Schröder HC, Perović-Ottstadt S, Wiens M, Batel R, Müller IM, Müller WEG (2004b) Differentiation capacity of the epithelial cells in the sponge Suberites domuncula. Cell Tissue Res 316:271-280

Schröder HC, Boreiko A, Korzhev M, Tahir MN, Tremel W, Eckert C, Ushijima H, Müller IM, Müller WEG (2006) Co-expression and functional interaction of silicatein with galectin: matrix-guided formation of siliceous spicules in the marine demosponge Suberites domuncula. J Biol Chem 281:12001-12009

Schulze FE (1904) Hexactinellida. Wissenschaftliche Ergebnisse der Deutschen Tiefsee-Expedition auf dem Dampfer "Valdivia" 1898-1899. Fischer, Stuttgart

Schulze P (1925) Zum morphologischen Feinbau der Kiesel schwammnadeln. Z Morphol Ökol Tiere 4:615-625

Shimizu K, Cha J, Stucky GD, Morse DE (1998) Silicatein alpha: cathepsin L-like protein in sponge biosilica. Proc Natl Acad Sci USA 95:6234-6238

Sommer H, Kröner A, Hauzenberger C, Muhongo S, Wingate MTD (2003) Metamorphic petrology and zircon geochronology of highgrade rocks from the central Mozambique Belt of Tanzania: crustal recycling of Archean and Palaeoproterozoic material during the Pan-African orogeny. J Metamorphic Geol 21:915-934

Sullivan CW (1986) Silicification in diatoms. In: Evered D, O'Connor M (eds) Silicon biochemistry. Wiley, Chichester, pp 59-89

Tabachnick KR (2002) Family Monorhaphididae Ijima, 1927. In: Hooper JNA, Van Soest RWM (eds) Systema porifera. Kluwer Academic, New York, pp 1264-1266

Thomas R (2000) Determination of water contents of granite melt inclusions by confocal laser Raman microprobe spectroscopy. Am Mineral 85:868-872

Thompson JD, Higgins DG, Gibson TJ (1994) CLUSTAL W: improving the sensitivity of progressive multiple sequence alignment through sequence weighting, positions-specific gap penalties and weight matrix choice. Nucleic Acids Res 22:46734680

Uriz MJ (2006) Mineral spiculogenesis in sponges. Can J Zool $84: 322-356$

Uriz MJ, Turon X, Becerro MA, Agell G (2003) Siliceous spicules and skeleton frameworks in sponges: origin, diversity, ultrastructural patterns, biological functions. Microsc Res Tech 62:279299

Walker JCG, Hays PB, Kasting JF (1981) A negative feedback mechanism for the long-term stabilization of the earths surface temperature. J Geophys Res 86:9776-9782

Wang X, Wang Y (2006) An introduction to the study on natural characteristics of sponge spicules and bionic applications. Adv Earth Sci 21:37-42

Wirth R (2004) Focused ion beam (FIB): a novel technology for advanced application of micro- and nanoanalysis in geosciences and applied mineralogy. Eur J Mineral 16:863-876 